\title{
Spinal RNF20-Mediated Histone H2B Monoubiquitylation Regulates mGluR5 Transcription for Neuropathic Allodynia
}

\author{
[DCheng-Yuan Lai, ${ }^{1 \star}$ Ming-Chun Hsieh, ${ }^{1 *}$ Yu-Cheng Ho, ${ }^{1} \odot$ Hsueh-Hsiao Wang, ${ }^{1}$ Dylan Chou, ${ }^{1,2}$ Yang-Cheng Wen, ${ }^{1,2}$ \\ Po-Sheng Yang, ${ }^{1,3}$ ๑ Jen-Kun Cheng, ${ }^{1,4}$ and ${ }^{-H}$ Hien-Yu Peng ${ }^{1}$ \\ ${ }^{1}$ Department of Medicine, Mackay Medical College, New Taipei, 25245, Taiwan, ${ }^{2}$ Department of Physiology, School of Medicine, College of Medicine, Taipei \\ Medical University, Taipei, 11031, Taiwan, ${ }^{3}$ Department of Surgery, and ${ }^{4}$ Department of Anesthesiology, Mackay Memorial Hospital, Taipei, 10491, Taiwan
}

To date, histone $\mathrm{H} 2 \mathrm{~B}$ monoubiquitination (H2Bub), a mark associated with transcriptional elongation and ongoing transcription, has not been linked to the development or maintenance of neuropathic pain states. Here, using male Sprague Dawley rats, we demonstrated spinal nerve ligation (SNL) induced behavioral allodynia and provoked ring finger protein 20 (RNF20)-dependent H2Bub in dorsal horn. Moreover, SNL provoked RNF20-mediated H2Bub phosphorylated RNA polymerase II (RNAPII) in the promoter fragments of $m G l u R 5$, thereby enhancing $m G l u R 5$ transcription/expression in the dorsal horn. Conversely, focal knockdown of spinal RNF20 expression reversed not only SNL-induced allodynia but also RNF20/H2Bub/RNAPII phosphorylation-associated spinal $m G l u R 5$ transcription/expression. Notably, TNF- $\alpha$ injection into naive rats and specific neutralizing antibody injection into SNL-induced allodynia rats revealed that TNF- $\alpha$-associated allodynia involves the RNF20/H2Bub/RNAPII transcriptional axis to upregulate mGluR5 expression in the dorsal horn. Collectively, our findings indicated TNF- $\alpha$ induces RNF20-drived H2B monoubiquitination, which facilitates phosphorylated RNAPII-dependent $m G l u R 5$ transcription in the dorsal horn for the development of neuropathic allodynia.

Key words: H2Bub; mGluR5; neuropathic pain; pRNAPII; RNF20

Significance Statement

Histone $\mathrm{H} 2 \mathrm{~B}$ monoubiquitination (H2Bub), an epigenetic post-translational modification, positively correlated with gene expression. Here, TNF- $\alpha$ participated in neuropathic pain development by enhancing RNF20-mediated H2Bub, which facilitates phosphorylated RNAPII-dependent $m G l u R 5$ transcription in dorsal horn. Our finding potentially identified neuropathic allodynia pathophysiological processes underpinning abnormal nociception processing and opens a new avenue for the development of novel analgesics.

\section{Introduction}

Epigenetic post-translational modifications, such as methylation, acetylation, phosphorylation, SUMOylation, and ubiquitylation

Received April 30, 2018; revised Aug. 16, 2018; accepted Aug. 30, 2018.

Author contributions: C.-Y.L., M.-C.H., Y.-C.H., and H.-Y.P. wrote the first draft of the paper; M.-C.H., Y.-C.H., P.-S.Y., J.-K.C., and H.-Y.P. edited the paper; H.-Y.P. designed research; C.-Y.L., M.-C.H., Y.-C.H., H.-H.W., D.C., Y.-C.W., and H.-Y.P. performed research; C.-Y.L., M.-C.H., Y.-C.H., H.-H.W., D.C., Y.-C.W., P.-S.Y., J.-K.C., and H.-Y.P. analyzed data; H.-Y.P. wrote the paper.

This work was supported by the Ministry of Science and Technology (Taipei, Taiwan) MOST 105-2628-B-715003-MY3 and 104-2320-B-715-004-MY3 to H.-Y.P., and MOST 105-2320-B-715-003-MY2 to Y.-C.H., Mackay Memorial Hospital MMH-MM-10206, MMH-MM-10302, MMH-MM-10403, MMH-MM-10503, MMH-MM-10608, and MMH-MM-10705 to H.-Y.P., and MMH-MM-10714 to Y.-C.H., and Department of Medicine, Mackay Medical College 1001A03, 1001B07, 1011B02, 1021B08, 1031A01, 1031B07, 1041B06, 1042A08, 1051B03, and $1061 \mathrm{~B} 03$ to H.-Y.P. and 1051B04 to Y.-C.H.

The authors declare no competing financial interests.

${ }^{*}$ C.-Y.L. and M.-C.H. contributed equally to this study.

Correspondence should be addressed to Dr. Hsien-Yu Peng, Department of Medicine, Mackay Medical College No.

46, Sec. 3, Zhongzheng Road, Sanzhi Dist, New Taipei, Taiwan 25245. E-mail:hsien.yu@gmail.com.

DOI:10.1523/JNEUROSCI.1069-18.2018

Copyright $\odot 2018$ the authors $\quad 0270-6474 / 18 / 389160-15 \$ 15.00 / 0$ of histone tails, crucially regulate gene transcription (Berger, 2007; Kouzarides, 2007; Patel and Wang, 2013). Among these modifications, histone $\mathrm{H} 2 \mathrm{~B}$ monoubiquitination (H2Bub) has gained attention because it is highly associated with transcriptionally active loci and elongated chromatin (Pavri et al., 2006; Minsky et al., 2008). H2Bub-mediated transcription is particularly linked to neuronal degeneration (Mohan et al., 2014) and differentiation (Ishino et al., 2014). Notably, H2Bub is implicated in synaptic plasticity for $\mathrm{H} 2 \mathrm{Bub}$ accompanies chemical-induced LTP in the murine hippocampus (Bach et al., 2015). Moreover, changes in the abundance of H2Bub in cortical pyramidal neurons are associated with deficits in learning behavior (Ouyang et al., 2015). Although pain-related spinal plasticity shares many features with LTP occurring in brain regions (Ji et al., 2003), the role of $\mathrm{H} 2 \mathrm{Bub}$-associated transcription elongation in the spinal plasticity underlying pain hypersensitivity is relatively unknown.

The protein ubiquitination cascade induced by ring finger proteins (RNFs), a family of E3 ubiquitin ligases, is a crucial post-translational modification (Alpi and Patel, 2009) and is im- 
plicated in neuronal pathology; RNF deficiency results in cognitive decline (Ouyang et al., 2015). RNF20, a member of RNF ligases, ubiquitinates Lys120 of histone H2B (Hwang et al., 2003); and RNF20-associated $\mathrm{H} 2 \mathrm{Bub}$ is coupled to gene transcription regulation (Shiloh et al., 2011). Intriguingly, RNF20-mediated H2Bub was shown to facilitate RNA polymerase II (RNAPII)dependent transcription (Pavri et al., 2006), which is marked by serine 2 (Ser2) phosphorylation of the RNAPII carboxyl-terminal domain (CTD) (Wu et al., 2014). Functional enrichment analysis of coexpression modules has revealed RNAPII and ubiquitindependent proteolysis are players in the etiology and development of neuropathic pain (Zhang et al., 2017). Furthermore, our previous studies have demonstrated spinal protein ubiquitination plays a key role in neuropathic pain (Lin et al., 2015b; Lai et al., 2016) and spinal RNAPII phosphorylation promotes transcriptional elongation of pain-associated genes to mediate pain development (Hsieh et al., 2017a). Therefore, we postulate that RNF20-mediated H2Bub contributes to neuropathic pain development by impacting RNAPII-dependent gene transcription in the dorsal horn.

TNF- $\alpha$, a proinflammatory cytokine, is implicated in pain development (Sorkin and Doom, 2000; Zimmermann, 2001). Importantly, TNF- $\alpha$ upregulates genes by regulating RNF20mediated H2Bub/RNAPII signaling (Ouyang et al., 2015). Moreover, our laboratory has recently demonstrated that TNF- $\alpha$-associated epigenetic machinery modifies transcription of pain-associated genes through RNAPII phosphorylation (Hsieh et al., 2017a), and spinal TNF- $\alpha$ contributes to neuropathic pain hypersensitivity by upregulating glutamatergic receptor expression by impacting protein ubiquitination and degradation (Lin et al., 2015b). Furthermore, epigenetic upregulation of metabotropic glutamate receptor subtype 5 (mGluR5), a member of glutamatergic receptor families, is linked to a spinal mechanism underlying neuropathic pain (Hsieh et al., 2017b). Based on these observations, we hypothesized that spinal RNF20-mediated H2Bub may impact $m G l u R 5$ transcription and contribute to the spinal plasticity underlying neuropathic pain development by activating RNAPII phosphorylation. Additionally, the contribution of TNF- $\alpha$ to neuropathic pain development through this RNF20/ $\mathrm{H} 2 \mathrm{Bub} / \mathrm{pRNAPII/mGluR5}$ signaling cascade was also investigated.

\section{Materials and Methods}

Animal preparations. Adult male Sprague Dawley rats weighing 200-250 $\mathrm{g}$ were used throughout this study. They were housed under approved conditions with a $12 \mathrm{~h} / 12 \mathrm{~h}$ light/dark cycle and with food and water available ad libitum. All animal procedures in this study were conducted in accordance with the guidelines of the International Association for the Study of Pain (Zimmermann, 1983) and were reviewed and approved by the Institutional Review Board of Taipei Medical University, Taipei, Taiwan.

Spinal nerve ligation (SNL)-induced neuropathic pain model. The SNL rat model, which mimics neuropathic pain, was performed previously described (Chung et al., 2004; Lin et al., 2015b; Lai et al., 2016). Briefly, rats were anesthetized under isoflurane anesthesia (induction, 5\%; maintenance, $2 \%$ in air). After an incision was made, the left L5 and L6 spinal nerves were carefully isolated from the surrounding tissue and then tightly ligated with 6-0 silk sutures. In the sham operation group, the surgical procedures were identical to the nerve-ligated animals, except that the silk sutures were left unligated.

Behavioral studies. To assess the development of mechanical allodynia, rats were placed individually in an opaque plastic cylinder, which was placed on a wire mesh and habituated for $1 \mathrm{~h}$ to allow acclimatization to the environment. von Frey monofilaments (Stoelting) were then applied to the plantar surface of the hindpaws of animals to measure the pawwithdrawal threshold (up-down method) according to a modification of a previously described method (Chaplan et al., 1994). The motor function of the animals was assessed by a Rota Rod apparatus (Panlab Harvard Apparatus). For acclimatization, the animals were subjected to three training trials at 3-4 h intervals on 2 separate days. During the training sessions, the rod accelerated from 4 to $30 \mathrm{rpm}$ over a $180 \mathrm{~s}$ period. During test sessions, the performance times of the rats were recorded up to a cutoff time of $180 \mathrm{~s}$. Three measurements were obtained at intervals of $5 \mathrm{~min}$ and were averaged for each test.

Intrathecal catheter implantation. The protocol for implantation of intrathecal cannulae was as described in our previous study (Lin et al., 2015b). Under isoflurane anesthesia, a PE-10 catheter was implanted in the dorsal aspect of lumbar enlargement of the spinal cord of rats. Once the catheter was in place, the outer part of the catheter was plugged and immobilized onto the skin on closure of the wound. After $3 \mathrm{~d}$ of recovery, animals with any sign of neurological deficits were discarded and excluded from further experiments.

Western blot analysis. Rats were deeply anesthetized, and dorsal horn (L4-L5) samples were immediately removed. The dissected samples were homogenized in $25 \mathrm{~mm}$ Tris- $\mathrm{HCl}, 150 \mathrm{~mm} \mathrm{NaCl}, 1 \% \mathrm{NP}-40,1 \%$ sodium deoxycholate, and $0.1 \%$ SDS supplemented with a complete protease inhibitor mixture (Roche). After incubation on ice $(1 \mathrm{~h})$, the lysates were centrifuged $\left(14,000 \mathrm{rpm}, 20 \mathrm{~min}, 4^{\circ} \mathrm{C}\right)$, and the supernatant was collected. The protein concentrations of each sample were determined using a BCA protein assay reagent kit (Pierce). Briefly, equal amounts of samples were separated by SDS-PAGE and electrophoretically transferred to PVDF membranes, which were then incubated ( $1 \mathrm{~h}$, room temperature) with rabbit anti-H2Bub (1:2000, Cell Signaling Technology), mouse anti-total H2B (1:2000, Millipore), rabbit anti-RNF20 (1:1000, Cell Signaling Technology), rabbit anti-pRNAPII (1:1000, Abcam), rabbit antimGluR5 (1:10000, Millipore), or mouse anti-GAPDH (1:2000, Genetex) antibodies. The blots were washed and incubated ( $1 \mathrm{~h}$, room temperature) with peroxidase-conjugated goat anti-rabbit IgG (1:8000, Jackson ImmunoResearch Laboratories) or goat anti-mouse IgG (1:8000, Jackson ImmunoResearch Laboratories) antibodies. The protein bands were visualized using an enhanced chemiluminescence detection kit (ECL Plus, Millipore) and then subjected to densitometric analysis using Science Lab 2003 (Fuji).

Immunofluorescence. The rats were deeply anesthetized and intracardially perfused with PBS followed by 4\% PFA/PBS, pH 7.4. Dorsal horn (L4-L5) samples were harvested, postfixed in $4 \%$ PFA $\left(4^{\circ} \mathrm{C}\right.$ for $\left.4 \mathrm{~h}\right)$, and cryoprotected overnight in a sucrose solution (30\%). Dorsal horn sections $(30 \mu \mathrm{M})$ were cut using a cryostat and processed for immunofluorescence. The sections were preincubated with 5\% BSA and 0.01\% Triton $\mathrm{X}-100$ in PBS to block nonspecific binding. Subsequently, the sections were incubated with rabbit anti-H2Bub (1:100, Cell Signaling Technology) together with mouse monoclonal anti-neuronal nuclear antigen (NeuN, a neuronal marker, 1:500, Millipore), mouse anti-GFAP (an astrocyte marker; 1:1000, Millipore), or mouse anti-integrin $\alpha \mathrm{M}$ (OX42, a microglial marker; 1:500, Santa Cruz Biotechnology) overnight $\left(4^{\circ} \mathrm{C}\right)$. After three rinses with PBS, the sections were then incubated $(1 \mathrm{~h}$, $\left.37^{\circ} \mathrm{C}\right)$ with AlexaFluor-488 (1:1500; Invitrogen) and AlexaFluor-594 (1: 1500; Invitrogen). To examine the interaction between RNF20 and $\mathrm{H} 2 \mathrm{Bub}$ and the interactions among H2Bub and pRNAPII, specific antibodies were mixed with $10 \times$ reaction buffer (Mix-n-Stain; Biotium) at a $1: 10$ ratio. The solution was then transferred to a vial containing dye (CF, Biotium) and incubated in the dark (30 min, room temperature). The sections were sequentially incubated (overnight, $4^{\circ} \mathrm{C}$ ) with diluted solutions: rabbit anti-H2Bub (1:100, Cell Signaling Technology), rabbit antiRNF20 (1:100, Cell Signaling Technology), and rabbit anti-pRNAPII (1:200, Abcam) antibodies, and washed 5 times between each incubation. The sections were subsequently rinsed in PBS, and coverslips were applied. After excitation, the fluorescent markers were easily detected using a camera-coupled device (X-plorer; Diagnostic Instruments) using fluorescence microscopy (DM2500, Leica Microsystems). For quantity measurement of immunofluorescent intensity, cell counting in the superficial dorsal horn was performed under a microscope at a magnification of $\times 200$. Five sections from each spinal cord were selected and six 
animals were analyzed in each group. Images were analyzed with ImageJ software.

$q R T-P C R$. The dissected dorsal horn (L4-L5) samples were quickly removed and completely submerged in a sufficient volume of RNAlater solution (AM7021; Ambion) overnight at $4^{\circ} \mathrm{C}$ to allow thorough penetration of the tissue and then transferred to $80^{\circ} \mathrm{C}$. Total RNA was isolated under RNase-free conditions using RNA isolation kits (74106; QIAGEN). Reverse transcription was performed using complementary DNA reverse transcription kits (205311; QIAGEN). Real-time PCR was performed on a QuantStudio 3 Real-Time PCR System (Thermo Fisher Scientific). TaqMan Universal PCR Master Mix $(2 \times)$ and gene expression assay probes for the target genes GAPDH (Rn.PT.58.35727291, IDT) and $m$ GluR5 (Rn.PT.58.36061021, IDT) were used. The reactions (total volume, $20 \mu \mathrm{l}$ ) were incubated at $95^{\circ} \mathrm{C}$ for $20 \mathrm{~s}$, followed by 40 cycles of $1 \mathrm{~s}$ at $95^{\circ} \mathrm{C}$ and $20 \mathrm{~s}$ at $60^{\circ} \mathrm{C}$. The relative mRNA levels were calculated using the $2^{-\delta \delta \mathrm{CT}}$ method.(Livak and Schmittgen, 2001) All CT values were normalized to GAPDH.

Chromatin immunoprecipitation-qPCR (ChIP). ChIP was performed using a ChIP kit (Millipore) according to a modified protocol by the manufacturer. Dissected dorsal horn (L4-L5) samples were cut into small pieces $\left(1-2 \mathrm{~mm}^{3}\right)$ using razor blades. The minced samples were treated with fresh $1 \%$ PFA in a PBS buffer by gentle agitation for $10 \mathrm{~min}$ at room temperature to cross-link the proteins to the DNA. Then, the tissues were washed and resuspended in lysis buffer, the lysates were sheared by sonication to generate chromatin fragments with an average length of $200-$ $1000 \mathrm{bp}$, and $1 \%$ of the sonicated chromatin was saved as an input control for the qPCR. The chromatin was then immunoprecipitated for $2 \mathrm{~h}$ at room temperature with rabbit anti-H2Bub (1:2000, Cell Signaling Technology), rabbit anti-RNF20 (1:1000, Cell Signaling Technology), rabbit anti-pRNAPII (1:1000, Abcam), or an equivalent amount of rabbit IgG ( $5 \mu \mathrm{g}$, Sigma-Aldrich). The protein-DNA immunocomplexes were precipitated overnight using protein $\mathrm{G}$ magnetic beads at $4^{\circ} \mathrm{C}$. After the beads were washed, they were resuspended in the ChIP elution buffer, incubated with proteinase $\mathrm{K}$ at $62^{\circ} \mathrm{C}$ for $2 \mathrm{~h}$, and then incubated at $95^{\circ} \mathrm{C}$ for $10 \mathrm{~min}$ to reverse the protein-DNA cross-links. The ChIP signals were quantified via a quantitative PCR analysis on a QuantStudio 3 Real-Time PCR System (Thermo Fisher Scientific). The specific primer pairs for the $m$ GluR5 promoter region are described below: $5^{\prime}$-GGGTTAGGGAGG GAAGAGAA-3' and 5'-GTGTGCACCATTTCAGCATC-3'.

Small-interfering RNA (siRNA). The siRNA targeting RNF20 was $5^{\prime}-$ GAGAUAACCUGAUAAUGGA-3'. The missense sequence was $5^{\prime}$ UGAUAUUACCCUGAAUAUG-3'. The missense or siRNA construct was intrathecally administered using a polyethyleneimine $(10 \mu \mathrm{l}$, Dharmacon)-based gene-delivery system. The RNF siRNA or missense siRNA was intrathecally injected daily for $4 \mathrm{~d}$ in naive rats or daily from days 3-6 after operation in sham and SNL rats.

Injection of adenovirus-associated vector. Recombinant adenoassociated virus (AAV) encoding RNF20 and GFP marker (AAV9RNF20-GFP) and AAV encoding GFP (AAV9-GFP) were purchased from Vigene Biosciences. For use, AAV9-RNF20-GFP and AAV9-GFP were diluted with PBS to $\sim 2.61 \times 10^{13}$ and $\sim 7.68 \times 10^{13}$ vector genomes $(\mathrm{vg}) / \mathrm{ml}$, respectively. AAV9-RNF20-GFP (10 $\mu \mathrm{l})$ was intrathecally injected into the subarachnoid space of L5-L6 spinal cord in naive rats using a microsyringe. Control rats were injected with the same amount of AAV9-GFP. RNF20 siRNA, missense siRNA, vehicle, or $\alpha$-amanitin was daily intrathecally injected on days 11-14 after the virus injection. Behavioral tests and sample analyses on day 14 after the virus injection.

Drugs and drug administration. MPEP (a mGluR5 antagonist; $300 \mathrm{nM}$, $10 \mu$; Tocris Bioscience), $\alpha$-amanitin (an inhibitor of RNAPII; $300 \mathrm{~nm}, 1$ $\mu \mathrm{M}, 3 \mu \mathrm{M} ; 10 \mu \mathrm{l}$; Tocris Bioscience), TNF- $\alpha$-neutralizing antibody (100 ng, $10 \mu$ li.t.; R\&D Systems) and TNF- $\alpha$ ( 1 pM, $10 \mu$ l; Sigma-Aldrich) were administered to the rats via multibolus intrathecal injections. A vehicle solution was administered at a volume identical to that of the tested agents to serve as a control.

Data analysis. All data in this study were analyzed using Sigma Plot 10.0 (Systat Software) or Prism 6.0 (GraphPad), and the results are expressed as the mean \pm SEM. Paired two-tailed Student's $t$ test was used to compare the means between groups. One-way or two-way ANOVAs were used to assess changes in values for serial measurements over time, and post hoc Tukey's tests were used to compare the means of groups. Significance was set at $p<0.05$.

\section{Results}

\section{SNL enhances H2Bub expression in the dorsal horn}

To examine the role of spinal H2Bub in the development of neuropathic pain, we used SD rats subjected SNL, an animal model mimicking neuropathic injury (Chaplan et al., 1994; Chung et al., 2004). Our procedure of SNL successfully induced tactile allodynia as evidenced by decrements in the withdrawal threshold of the ipsilateral hind paw of rats on days 3, 7, 14, and 21 after operation $(5.68 \pm 1.40 \mathrm{~g}, 2.00 \pm 0.73 \mathrm{~g}, 2.61 \pm 0.63 \mathrm{~g}$, and $2.39 \pm$ $0.97 \mathrm{~g}$; two-way ANOVA, group, $F_{(3,20)}=26.86, p<0.0001$; time, $F_{(4,80)}=4.281, p=0.0034$; interaction, $F_{(12,80)}=4.590, p<$ $0.0001 ; n=6$; Fig. $1 A$ ). Moreover, SNL increased the expression of $\mathrm{H} 2 \mathrm{Bub}$ in the ipsilateral dorsal horn on day 7 after operation $\left(0.47 \pm 0.04\right.$; two-way ANOVA, group, $F_{(3,16)}=6.600, p=$ 0.0041 ; time, $F_{(1,16)}=20.23, p=0.0004$; interaction, $F_{(3,16)}=$ 16.70, $p<0.0001 ; n=5$; Fig. $1 B$ ). To determine the cellular distribution of $\mathrm{H} 2 \mathrm{Bub}$ in the dorsal horn, we next labeled spinal cord slices dissected at day 7 after SNL using specific antibodies. SNL enhanced H2Bub immunofluorescence in the ipsilateral dorsal horn on day 7 after operation (one-way ANOVA, $F_{(3,20)}=$ 15.02, $p<0.0001, n=6$; Fig. $1 C$ ), which was largely colocalized with neuronal (NeuN) but also rarely done with microglial (OX42) and astrocytic (GFAP) markers. Collectively, these results indicated SNL increased H2Bub expression largely in neurons but also minor in astrocyte and microglia in the ipsilateral dorsal horn.

\section{SNL enhances RNF20 expression and coupling to H2Bub in the dorsal horn}

Because H2Bub depends on RNF20 activity (Foglizzo et al., 2016), we postulated RNF20 might mediate the SNL-enhanced spinal H2Bub expression. To validate this hypothesis, we first examined the RNF20-H2bub interaction after SNL using immunofluorescence analysis. As anticipated, images of spinal slices revealed SNL enhanced RNF20-positive, H2Bub-positive, and RNF20/H2Bub double-labeled immunofluorescence in the ipsilateral dorsal horn (Fig. 2A). We next assessed the expression profiles of RNF20 in the dorsal horn in response to SNL. Interestingly, consistent with behavioral allodynia and enhanced H2Bub expression, SNL increased the abundance of RNF20 in the ipsilateral dorsal horn samples $(0.31 \pm 0.04$; two-way ANOVA; group, $F_{(3,16)}=7.159, p=0.0029$; time, $F_{(1,16)}=15.13$, $p=0.0013$; interaction, $F_{(3,16)}=12.95, p=0.0002 ; n=5$; Fig. $2 B)$. These results suggested that, in addition to enhancing the abundance of H2Bub, SNL upregulated RNF20 expression and RNF20-H2Bub coupling in the ipsilateral dorsal horn.

\section{Knockdown of spinal RNF20 expression attenuates SNL-induced allodynia and $\mathrm{H} 2 \mathrm{Bub}$ expression}

Based on above observations, we next used siRNA targeting the RNF20 gene to validate the role of spinal RNF20 in neuropathic pain as well as the upstream and downstream relationships between RNF20 and H2Bub. RNF20 siRNA (1, 3, and $5 \mu \mathrm{g} ; 10 \mu \mathrm{l}$; once daily for $4 \mathrm{~d}$ ) dose-dependently reduced RNF20 expression in the dorsal horn of naive rats (from $0.14 \pm 0.01$ to $0.07 \pm 0.01$, $0.06 \pm 0.01$, and $0.04 \pm 0.01$; one-way ANOVA, $F_{(6,28)}=14.29$, $p<0.0001, n=5$; Fig. $3 A$ ), which confirmed the efficacy and specificity of our knockdown protocols. The naive and RNF20 
A

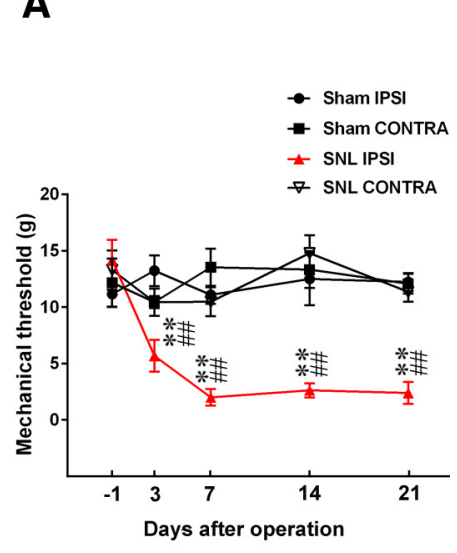

B

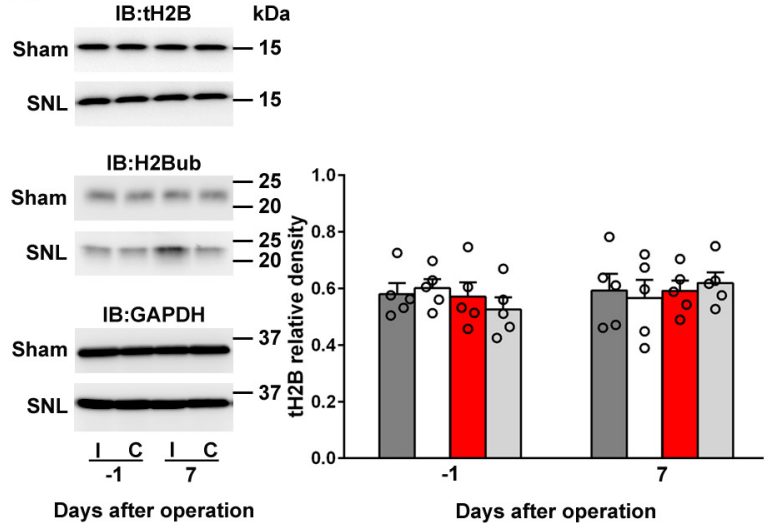

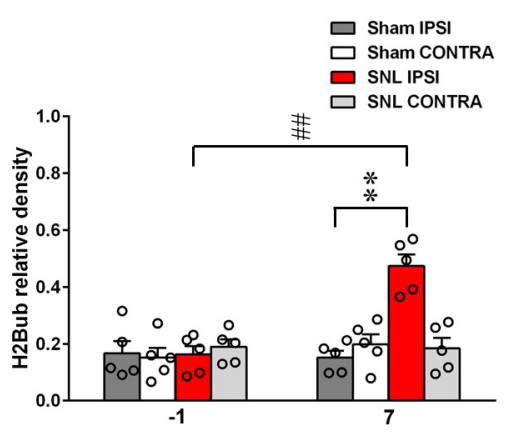

Days after operation
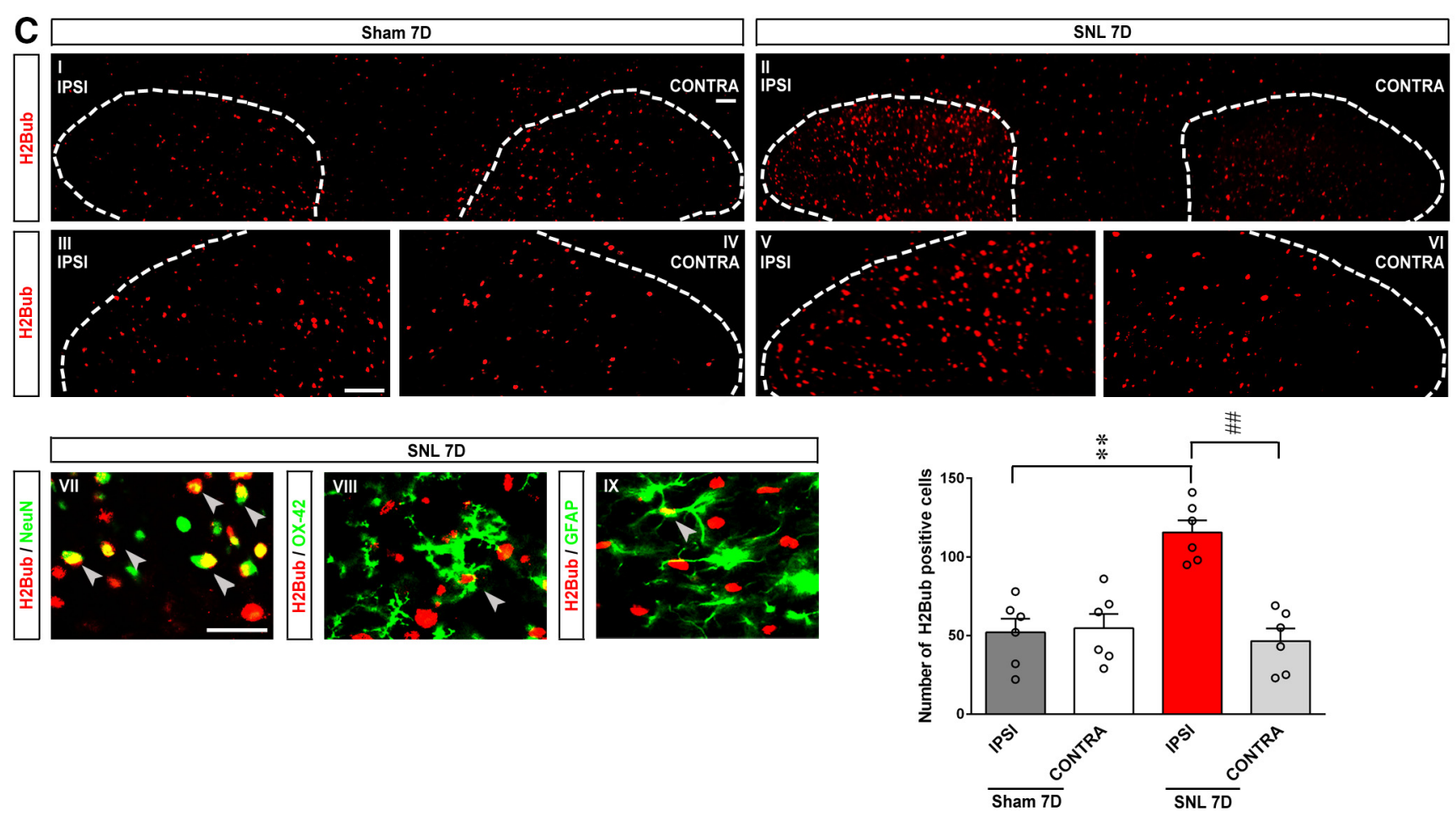

Figure 1. SNL upregulates $\mathrm{H} 2 \mathrm{Bub}$ expression in the dorsal horn accompanied by behavioral allodynia. $\boldsymbol{A}$, Time course of SNL decreased the ipsilateral paw withdrawal threshold after operation. Sham, Sham operation group; IPSI, ipsilateral. CONTRA, contralateral. ${ }^{* *} p<0.01$ versus Sham IPSI. ${ }^{\# \#} p<0.01$ versus day $-1 . \boldsymbol{B}$, Representative Western blot and statistical analyses (normalized to GAPDH) demonstrating that SNL increased H2Bub, not $\mathrm{tH} 2 \mathrm{~B}$, expression in the ipsilateral dorsal horn on day 7 after operation. IB, Immunoblotting; $\mathrm{I}$, ipsilateral; $C$, contralateral. ${ }^{* *} p<0.01$ versus Sham IPSI. ${ }^{\#} p<0.01$ versus day -1. C, In the ipsilateral dorsal horn, SNL (SNL 7D) increased H2Bub immunofluorescence (red, II, V), which colocalized with NeuN (green, VII, a neuronal marker), GFAP (green, VIII, an astrocytic marker), or OX-42 (green, IX, a microglial marker) at day 7 after operation. Scale bar, $50 \mu \mathrm{m}$. Thickness $=30 \mu \mathrm{m} .{ }^{* *} p<0.01$ versus Sham IPSI. ${ }^{\# \#} p<0.01$ versus SNL CONTRA.

siRNA ( $5 \mu \mathrm{g}, 10 \mu \mathrm{l})$-treated groups exhibited no significant differences in motor performance measured by the rotarod test (two-way ANOVA; group, $F_{(3,20)}=1.651, p=0.2095$; time, $F_{(4,80)}=2.193, p=0.0771$; interaction, $F_{(12,80)}=0.8161, p=$ $0.6333 ; n=6$; Fig. $3 B$ ), indicating that neither our procedures nor RNF20 siRNA itself led to motor deficits in rats. Moreover, while RNF20 siRNA (5 $\mu \mathrm{g}, 10 \mu \mathrm{l}$, daily from days 3-6 after SNL) exhibited no effects on the paw withdrawal threshold of sham operation (two-way ANOVA; group, $F_{(3,20)}=1.837, p=0.1729$; time, $F_{(4,80)}=1.233, p=0.3035$; interaction, $F_{(12,80)}=0.8836$, $p=0.5666 ; n=6$; Fig. $3 C$ ), it markedly reversed the reduced the ipsilateral paw withdrawal threshold $(8.30 \pm 1.53 \mathrm{~g}$; two-way ANOVA; group, $F_{(3,20)}=3.200, p=0.0455$; time, $F_{(4,80)}=97.48$, $p<0.0001$; interaction, $F_{(12,80)}=4.240, p<0.0001 ; n=6$; Fig.
3D) and suppressed the enhanced RNF20 and H2Bub amounts in the ipsilateral dorsal horn of SNL rats (from $0.33 \pm 0.03$ to $0.16 \pm$ 0.03 and from $0.53 \pm 0.04$ to $0.33 \pm 0.02$; RNF20, one-way ANOVA, $F_{(3,16)}=13.65, p=0.0001, n=5$; H2Bub, one-way ANOVA, $F_{(3,16)}=25.89, p<0.0001, n=5$; Fig. $\left.3 E\right)$. Furthermore, immunofluorescence images showed that intrathecal administration of RNF20 siRNA ( $5 \mu \mathrm{g}, 10 \mu \mathrm{l}$; Fig. $3 F$ ) to SNL rats reduced the count of SNL-enhanced RNF20-positive, H2Bubpositive, and RNF20/H2Bub double-labeled immunofluorescence in the ipsilateral dorsal horn. In addition to revealing spinal RNF20 as a crucial player in the development of neuropathic pain, these results also suggest that spinal H2Bub acts downstream of RNF20 in mediating neuropathic pain hypersensitivity. 
SNL-enhanced RNF20/H2Bub signaling modifies mGluR5 transcription/

expression in the dorsal horn

RNF20 facilitates H2Bub, a well-known epigenetic modification mark (Minsky et al., 2008), in target genes for transcription elongation (Shiloh et al., 2011). Because post-translational modification crucially impacts mGluR5 expression (Matosin et al., 2017), and epigenetically enhanced spinal mGluR5 expression contributes to the genesis of pain hypersensitivity (Hsieh et al., 2017b; Zhou et al., 2017), we postulated the SNL-activated RNF20/H2Bub cascade mediates the development of neuropathic pain by modifying spinal mGluR5 expression. To validate this hypothesis, we first intrathecally administered MPEP (a mGluR5 antagonist; 300 $\mathrm{nM}, 10 \mu \mathrm{l}$; daily from days 3-6 after SNL) to SNL rats. Supporting our hypothesis, this treatment ameliorated SNL-induced behavioral allodynia (from $2.16 \pm 0.61 \mathrm{~g}$ to $6.91 \pm 1.04$ g; one-way ANOVA, $F_{(3,20)}=$ 26.26, $p<0.0001, n=6$; Fig. $4 A$ ). RTPCR and Western blot analyses revealed that SNL increased the mRNA and protein expression levels of mGluR5 in the ipsilateral dorsal horn (from $0.94 \pm 0.15$ to $3.06 \pm 0.24$ and from $0.09 \pm 0.02$ to $0.29 \pm 0.03)$, which were markedly inhibited by RNF20 siRNA ( $5 \mu \mathrm{g}, 10 \mu \mathrm{l} ; 1.79 \pm$ 0.14 and $0.13 \pm 0.01 ;$ mRNA, one-way ANOVA, $F_{(3,16)}=23.97, p<0.0001, n=$ 5 ; protein, one-way ANOVA, $F_{(3,16)}=$ $13.66, p=0.0001, n=5$; Fig. $4 B, C)$. Moreover, a ChIP-qPCR assay revealed that more $m G l u R 5$ promoter fragments were immunoprecipitated by RNF20- and H2Bubspecific antibodies in the ipsilateral dorsal horn samples of SNL compared with the sham-operated rats (from $0.05 \pm 0.01$ to $0.10 \pm 0.01$ and from $1.04 \pm 0.18$ to $2.42 \pm$ $0.20)$; this effect was blunted by RNF20 siRNA $(5 \mu \mathrm{g}, 10 \mu \mathrm{l} ; 0.06 \pm 0.01$ and $1.62 \pm$ 0.13; RNF20, one-way ANOVA, $F_{(3,16)}=$ $12.74, p=0.0002, n=5$; H2Bub, one-way ANOVA, $F_{(3,16)}=16.36, p<0.0001, n=5$; Fig. $4 D$ ) administered to SNL rats, indicat-

ing that RNF20 coordinates with $\mathrm{H} 2 \mathrm{Bub}$ coupling to the mGluR5 promoter in the ipsilateral dorsal horn after SNL. Collectively, these data indicated that RNF20/H2Bub signaling regulates mGluR5 expression in the dorsal horn after SNL.

Spinal RNF20/H2Bub-mediated mGluR5 expression requires RNAPII phosphorylation in SNL rats

Phosphorylation of the CTD of RNAPII (pRNAPII) is an important step in transcription (Napolitano et al., 2000). Notably, RNF20-mediated H2Bub regulates the transcription of target genes through RNAPII-dependent elongation (Pavri et al., 2006; Wu et al., 2014). Moreover, our previous studies demonstrated spinal RNAPII phosphorylation promotes transcriptional elonga-
A
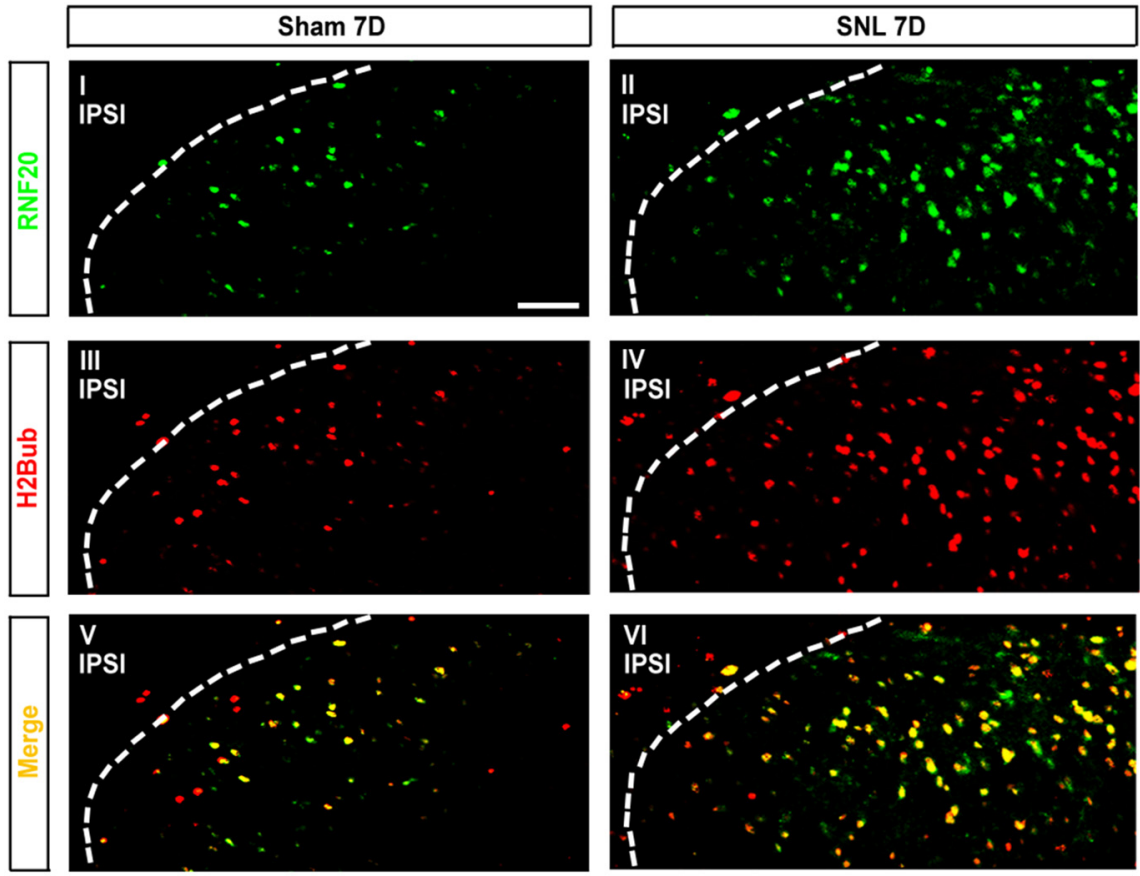

B

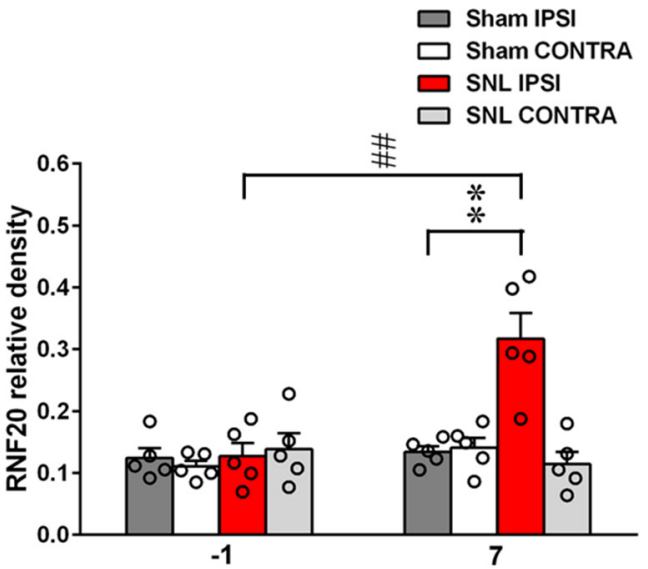

Days after operation

Figure 2. SNL enhances RNF2O expression and coupling with H2Bub in the dorsal horn. $\boldsymbol{A}$, Image analysis demonstrating that SNL (SNL 7D) increased RNF20-positive (green, II), H2Bub-positive (red, IV), and RNF20/H2Bub double-labeled (yellow, VI) immunofluorescence ipsilateral dorsal horn at day 7 after operation. Scale bar, $50 \mu \mathrm{m}$. Thickness $=30 \mu \mathrm{m}$. $\boldsymbol{B}$, Representative Western horn on day 7 after operation. IB, Immunoblotting; Sham, sham operation group; I, ipsilateral; IPSI, ipsilateral; C, contralateral; CONTRA, contralateral. ${ }^{* *} p<0.01$ versus Sham IPSI. ${ }^{\# \#} p<0.01$ versus day -1 .

tion of pain-associated genes to mediate pain development (Hsieh et al., 2017a). Therefore, we further identified the role of pRNAPII in RNF20/H2Bub-modified spinal mGluR5 expression provoked by SNL. As expected, immunofluorescence images revealed that SNL enhanced H2Bub-positive, pRNAPII-positive, and H2Bub/pRNAPII double-labeled immunofluorescence in the ipsilateral dorsal horn (Fig. $5 A$ ); these effects were inhibited by RNF20 siRNA ( $5 \mu \mathrm{g}$, $10 \mu \mathrm{l})$. Western blot analysis and ChIP-qPCR consistently demonstrated that SNL increased the amounts of pRNAPII and pRNAPII antibody-recognized $m G l u R 5$ promoter fragments in the ipsilateral dorsal horn samples (from $0.13 \pm 0.03$ to $0.69 \pm 0.06$ and from $1.93 \pm 0.29$ to $7.16 \pm 0.46, n=5$ ); these effects were reversed by treating the SNL animals with RNF20 siRNA ( $5 \mu \mathrm{g}, 10 \mu \mathrm{l} ; 0.36 \pm$ 0.06 and $4.85 \pm 0.61$; Fig. $5 B$, one-way ANOVA, $F_{(3,16)}=24.67, p<$ 
A

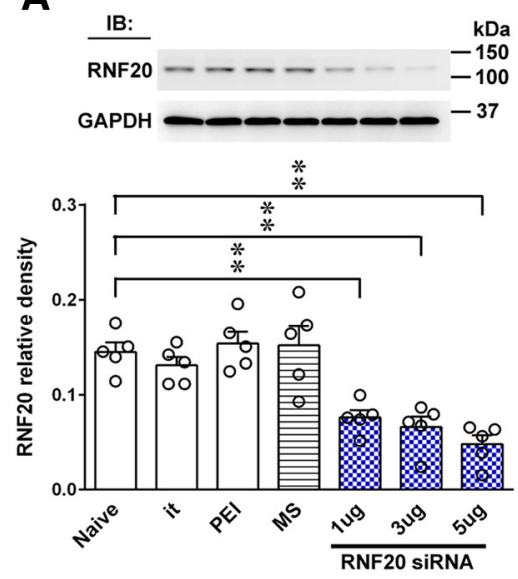

C

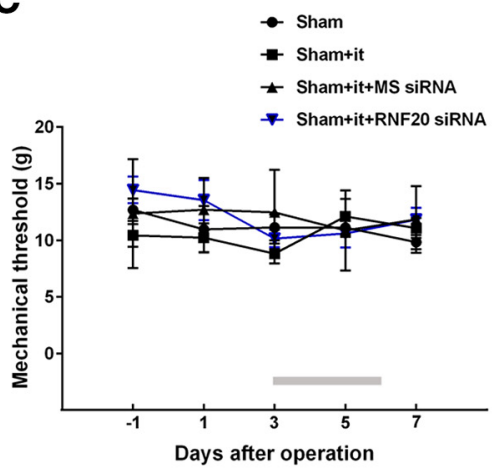

B

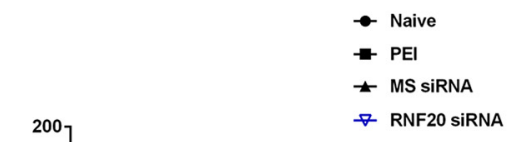

D

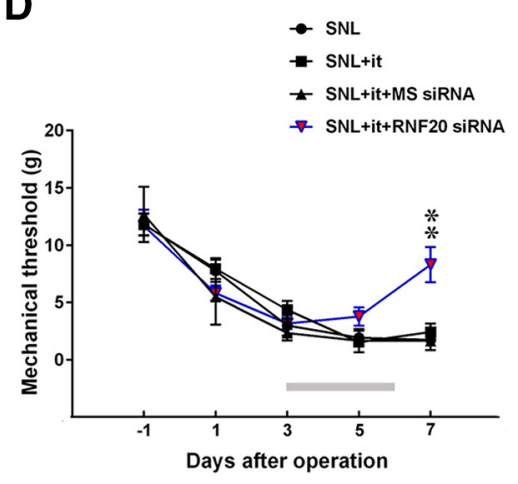

E

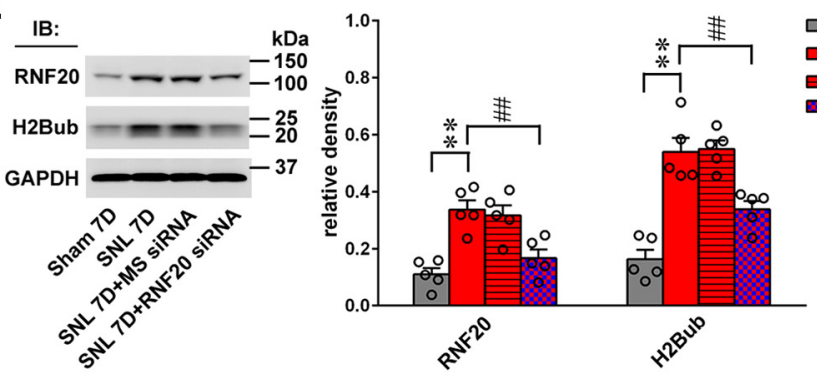

$\mathbf{F}$
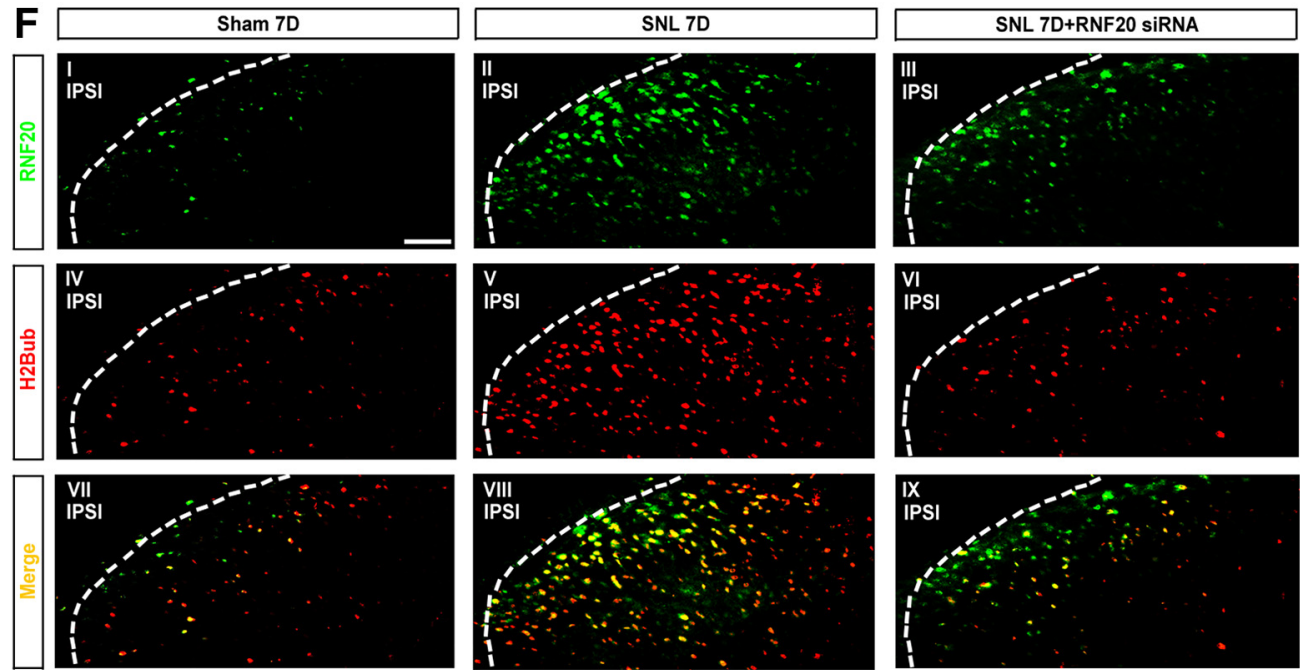

Figure 3. Knockdown of spinal RNF20 expression relieves SNL-induced allodynia. A, Representative Western blot and statistical analysis (normalized to GAPDH) demonstrating that intrathecal administration of RNF20 siRNA (RNF20 siRNA; 1, 3, and $5 \mu \mathrm{g} ; 10 \mu \mathrm{l}$; once daily for $4 \mathrm{~d}$ ), but not missense siRNA (MS siRNA, $5 \mu \mathrm{g}, 10 \mu \mathrm{l}$ ), polyethylenimine (PEl, a transfection reagent, $10 \mu \mathrm{l}$ ), or intrathecal puncture (it), led to a dose-dependent decrease in RNF20 levels in the dorsal horn of naive rats. IB, Immunoblotting. ${ }^{* *} p<0.01$ versus Naive. $\boldsymbol{B}$, Rotarod test (Figure legend continues.) 
A

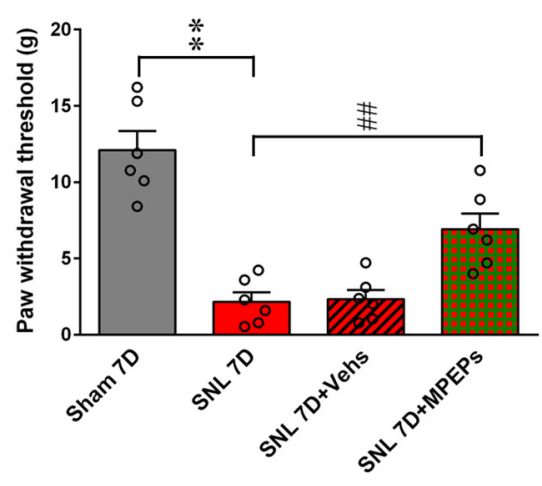

D

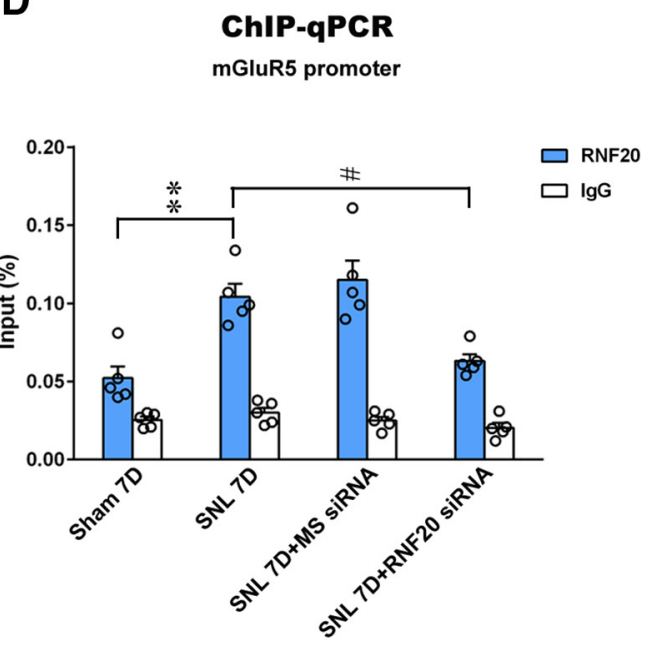

B

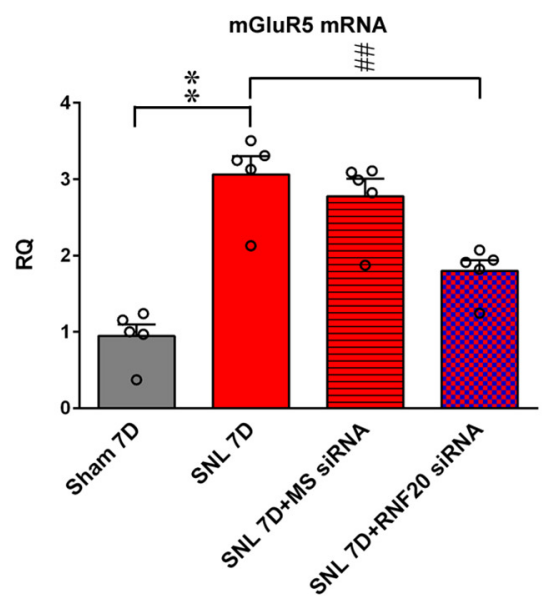

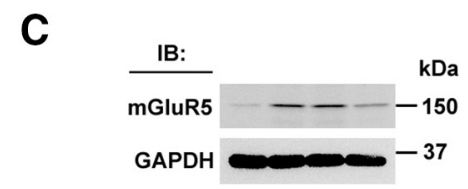

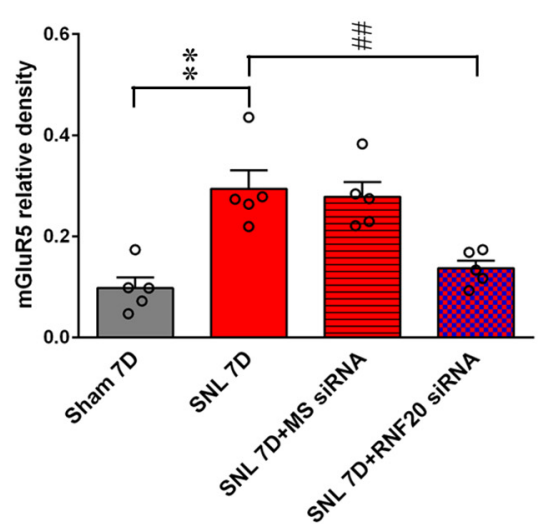

ChIP-qPCR

mGluR5 promoter

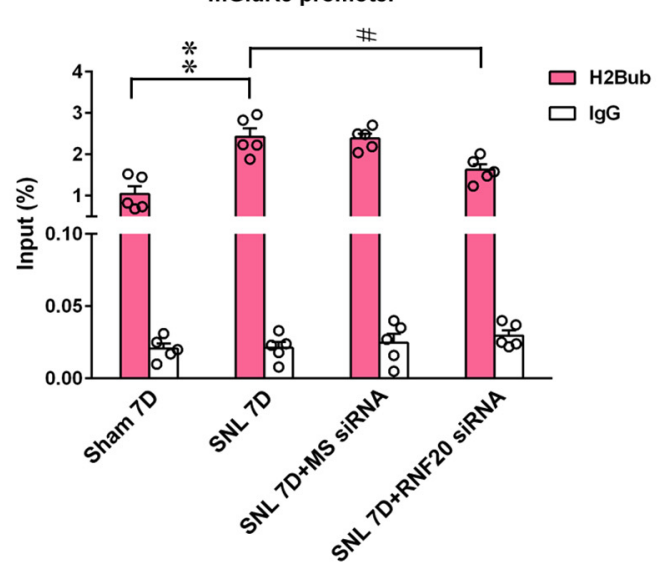

Figure 4. SNL increases RNF20/H2Bub signaling to enhance mGluR5 transcription/expression in the dorsal horn. $A$, Intrathecal MPEP (a mGluR5 antagonist, SNL 7D + MPEPs, $300 \mathrm{~nm}, 10 \mu \mathrm{l}$, daily from days $3-6$ after SNL operation) significantly increased the ipsilateral paw withdrawal threshold of SNL rats. ${ }^{* *} p<0.01$ versus Sham 7D. ${ }^{\# \#} p<0.01$ versus SNL 7D. B, C, Intrathecal RNF20 siRNA (SNL 7D+RNF20 siRNA, $5 \mu \mathrm{g}, 10 \mu \mathrm{l}$, daily from days 3-6 after SNL operation) inhibited SNL-enhanced expression levels of mGluR5 mRNA and protein in the ipsilateral dorsal horn. MS siRNA, Missense siRNA; IB, immunoblotting. ${ }^{* *} p<0.01$ versus Sham 7D. ${ }^{\#} p<0.01$ versus SNL 7D. D. Intrathecal RNF20 siRNA (SNL 7D + RNF20 siRNA, $5 \mu \mathrm{g}, 10 \mu \mathrm{l}$, daily from days $3-6$ after SNL operation) inhibited the SNL-induced abundance of $m G$ luR5 promoter fragments immunoprecipitated by RNF2O- and H2Bub-specific antibodies in the ipsilateral dorsal horn. ${ }^{* *} p<0.01$ versus Sham 7D. $" p<0.05$ versus SNL 7D.

0.0001, $n=5$; Fig. 5C, one-way ANOVA, $F_{(3,16)}=25.10, p<0.0001$, $n=5$; Fig. $5 B, C$ ). Moreover, intrathecal administration of MPEP (a mGluR5 antagonist; $300 \mathrm{~nm} ; 10 \mu$; daily from days 3-6 after SNL) to SNL rats reversed SNL-enhanced mGluR5 (from $0.29 \pm 0.03$ to

(Figure legend continued.) showing that application of RNF20 siRNA (RNF20 siRNA, $5 \mu \mathrm{g}, 10 \mu \mathrm{l}$, once daily for $4 \mathrm{~d}$ ) resulted in no motor deficits in rats (rotarod test). Bottom, Gray bar represents the duration of intrathecal administration. $C, D$, Although it exhibited no effect on paw withdrawal threshold in sham rats (Sham + it + RNF20 siRNA, $5 \mu \mathrm{g}, 10 \mu \mathrm{l}$, daily from days 3-6 after sham operation), RNF20 siRNA (SNL + it + RNF20 siRNA, $5 \mu \mathrm{g}, 10 \mu$, daily from days 3-6after SNL operation) significantly increased the ipsilateral paw withdrawal threshold of the SNL group. ${ }^{* *} p<0.01$ versus SNL. $\boldsymbol{E}$, Representative Western blot and statistical analyses (normalized to GAPDH) demonstrating that SNL-enhanced RNF20 and H2Bub expression levels in the ipsilateral dorsal horn were attenuated by administration of RNF20 siRNA (SNL 7D + RNF20 siRNA, $5 \mu \mathrm{g}, 10 \mu \mathrm{l}$, daily from days 3-6after SNL operation). ${ }^{* *} p<0.01$ versus Sham 7D. ${ }^{\# \#} p<0.01$ versus SNL 7D. F, Images showing that RNF20 siRNA (SNL 7D + RNF20 siRNA, $5 \mu \mathrm{g}, 10 \mu$, daily from days 3-6 after SNL operation) reversed SNL (SNL 7D)-enhanced RNF2O-positive (green), H2Bub-positive (red), and RNF2O/H2Bub double-labeled (yellow) immunofluorescence ipsilateral dorsal horn at day 7 after operation. Scale bar, $50 \mu \mathrm{m}$. Thickness $=30 \mu \mathrm{m}$.
$0.10 \pm 0.02)$, but not RNF20, H2Bub, or pRNAPII expression, in the ipsilateral dorsal horn (RNF20, one-way ANOVA, $F_{(3,16)}=33.82$, $p<0.0001, n=5$; H2Bub, one-way ANOVA, $F_{(3,16)}=23.44, p<$ 0.0001, $n=5$; pRNAPII, one-way ANOVA, $F_{(3,16)}=65.12, p<$ $0.0001, n=5$; mGluR5, one-way ANOVA, $F_{(3,16)}=18.99$, $p<0.0001, n=5$; Fig. $5 D$ ). To further validate the role of spinal pRNAPII in neuropathic pain as well as the upstream and downstream relationships between signaling pathway, we next used an inhibitor of RNAPII, $\alpha$-amanitin. Supporting above results, $\alpha$-amanitin (300 nM, 1, and $3 \mu \mathrm{M} ; 10 \mu \mathrm{l}$; daily from days 3-6 after SNL) dose-dependently ameliorated SNL-induced behavioral allodynia (from $1.51 \pm 0.63 \mathrm{~g}$ to $6.34 \pm 0.85 \mathrm{~g}, 8.08 \pm 1.31 \mathrm{~g}$, and $9.47 \pm$ 0.60 g; one-way ANOVA, $F_{(5,30)}=27.33, p<0.0001, n=6$; Fig. $\left.5 E\right)$. Intrathecal administration of $\alpha$-amanitin $(3 \mu \mathrm{M}, 10 \mu \mathrm{l}$, daily from days 3-6 after SNL) to SNL rats reversed SNL-enhanced the mGluR5 mRNA (from $3.11 \pm 0.53$ to $1.41 \pm 0.22$ ), mGluR5 (from $0.33 \pm 0.03$ to $0.14 \pm 0.02$ ), and pRNAPII expression (from $0.65 \pm$ 0.05 to $0.33 \pm 0.04$ ), but not RNF20 or H2Bub expression, in the ipsilateral dorsal horn (mGluR5 mRNA, one-way ANOVA, $F_{(3,16)}=$ 

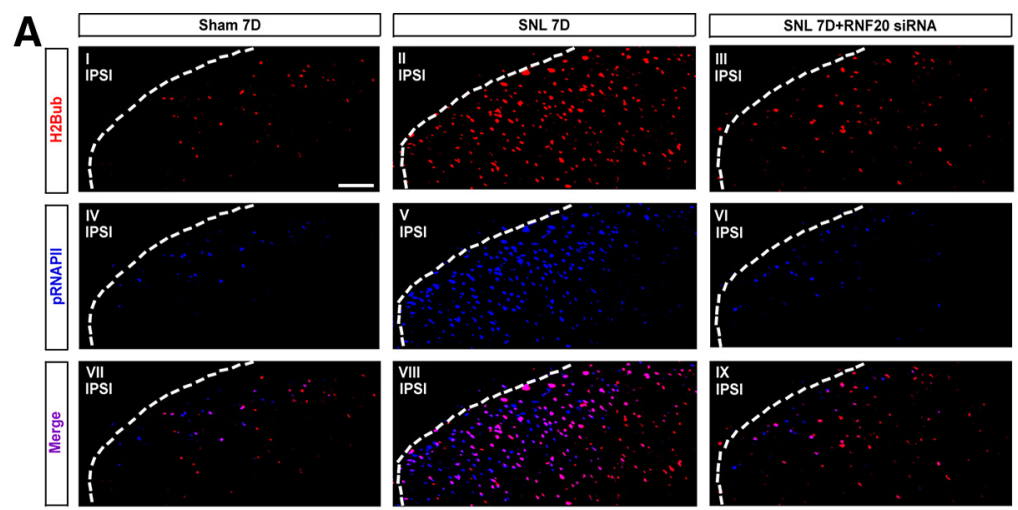

B

C

D

$\frac{\text { IB: }}{\text { RNF20 }}$
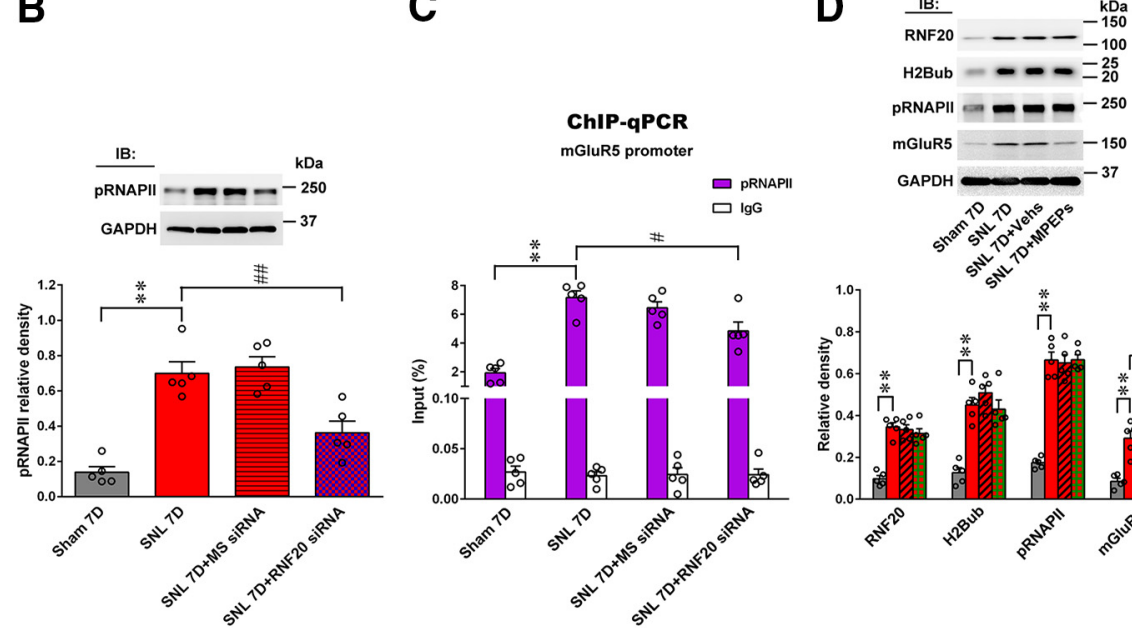

H2Bub - - - - - 25

PRNAPII $=---250$

mGluR5

GAPDH -37

$0^{20}$

E

$\mathbf{F}$
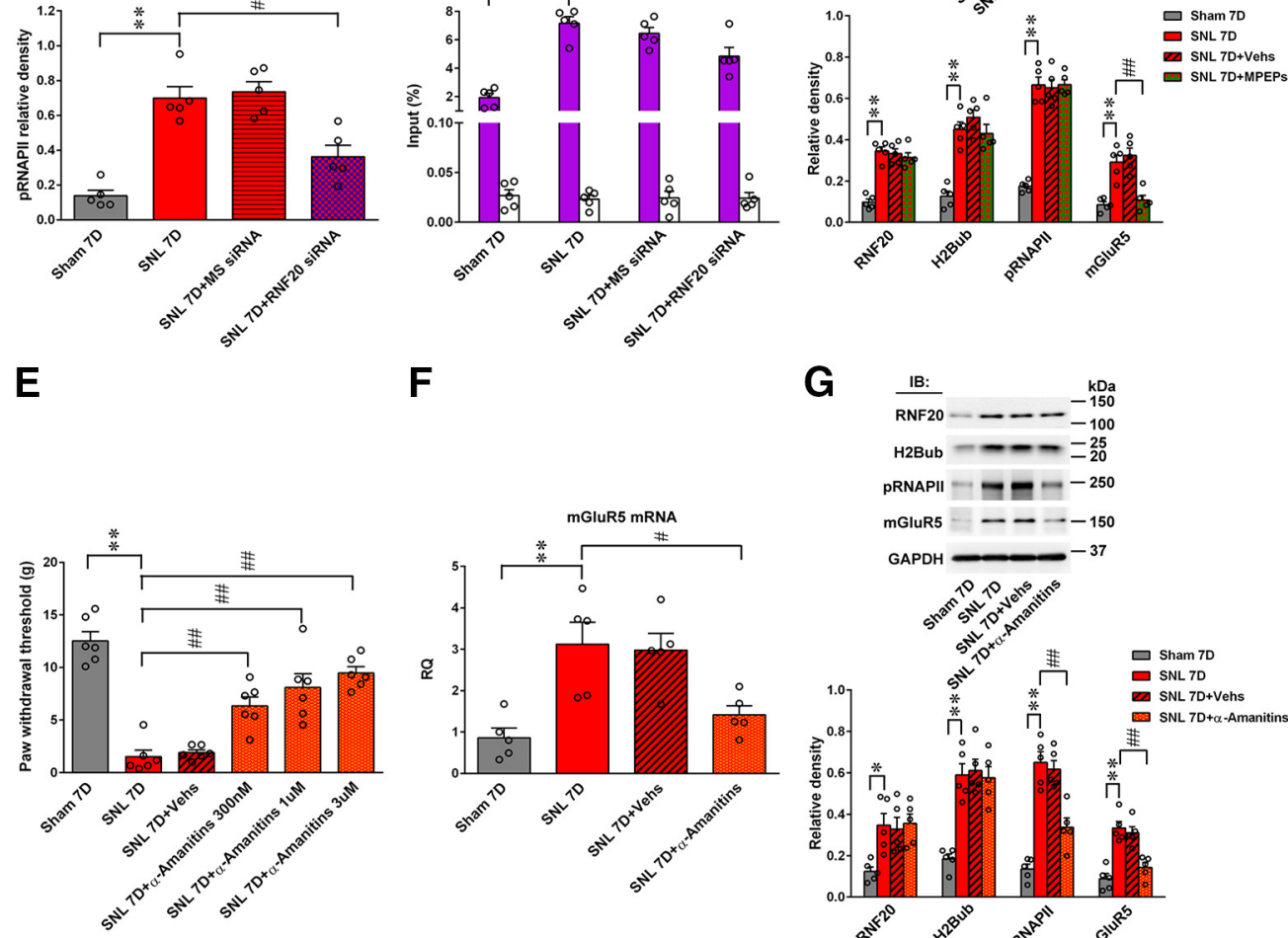

G
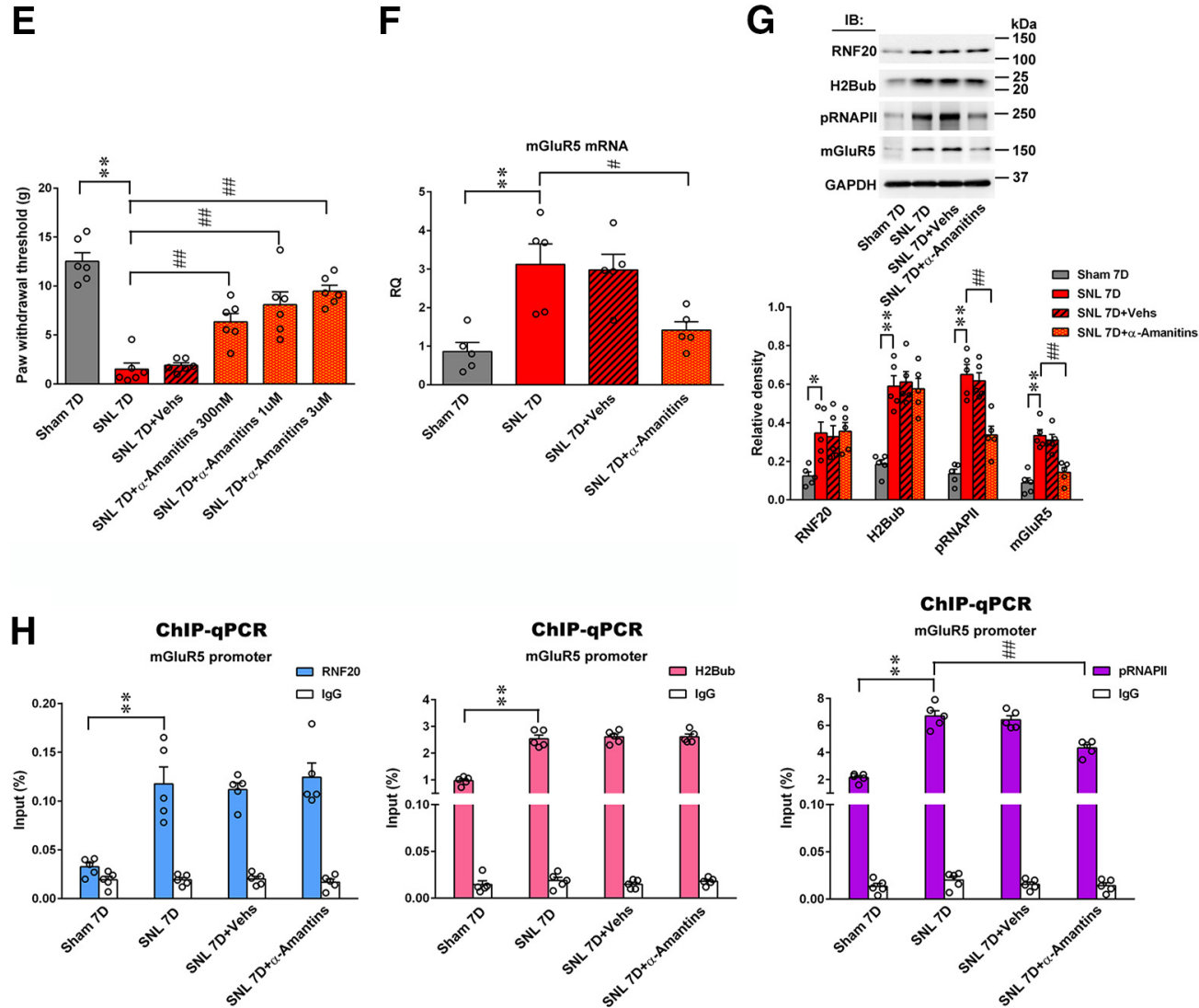

Figure 5. SNL provokes RNF20/H2Bub/pRNAPII-dependent mGluR5 activation in the dorsal horn. $A$, Images showing SNL (SNL 7D)-enhanced H2Bub-positive (red), pRNAPII-positive (blue), and pRNAPII/H2Bub double-labeled (purple) immunofluorescence ipsilateral dorsal horn at day 7 after operation; these effects were attenuated by administration of RNF20 siRNA (SNL 7D + RNF20 siRNA, $5 \mu \mathrm{g}, 10 \mu \mathrm{l}$, daily from days 3-6 after SNL operation). Scale bar, $50 \mu \mathrm{m}$. Thickness $=30 \mu \mathrm{m}$. B, Representative Western blot and statistical analyses (normalized (Figure legend continues.) 
9.265, $p=0.0009, n=5$; RNF20, one-way ANOVA, $F_{(3,16)}=5.418$, $p=0.0091, n=5$; H2Bub, one-way ANOVA, $F_{(3,16)}=17.57, p<$ 0.0001, $n=5$; pRNAPII, one-way ANOVA, $F_{(3,16)}=34.06, p<$ $0.0001, n=5$; mGluR5, one-way ANOVA, $F_{(3,16)}=19.56$, $p<0.0001, n=5$; Fig. $5 F, G)$. Furthermore, ChIP-qPCR demonstrated that intrathecal injection of $\alpha$-amanitin $(3 \mu \mathrm{M}, 10 \mu \mathrm{l})$ into SNL-treated rats significantly decreased pRNAPII antibodyrecognized $m G l u R 5$ promoter fragments (from $6.70 \pm 0.39$ to $4.34 \pm 0.25, n=5$ ), but not RNF20 and H2Bub, in the ipsilateral dorsal horn samples (RNF20, one-way ANOVA, $F_{(3,16)}=12.94, p=$ $0.0002, n=5$; H2Bub, one-way ANOVA, $F_{(3,16)}=56.63, p<0.0001$, $n=5$; pRNAPII, one-way ANOVA, $F_{(3,16)}=54.78, p<0.0001, n=$ 5; Fig. $5 H$ ). Collectively, these data indicated that SNL-enhanced RNF20/H2Bub transcriptionally regulates $m G l u R 5$ gene expression through its association with and regulation of pRNAPII in the ipsilateral dorsal horn.

\section{Intrathecal RNF20 gene transfer induces pain hypersensitivity by RNF20/H2Bub/pRNAPll/mGluR5 signaling pathway}

To provide direct evidence supporting the involvement of spinal RNF20/H2Bub/pRNAPll/mGluR5 signaling in pain hypersensitivity, the recombinant AAV encoding RNF20 and GFP (AAVRNF20) was intrathecally injected into naive rats. Control littermates were injected with AAV encoding GFP (AAVControl). First, Western blots confirmed that intrathecal injection of AAV encoding RNF20 (AAV-RNF20) into naive rat increased RNF20 expression in the dorsal horn at days 14 after intrathecal injection $\left(0.20 \pm 0.02\right.$; one-way $\operatorname{ANOVA,} F_{(2,12)}=$ 8.270, $p=0.0055, n=5$; Fig. $6 A$ ). Moreover, intrathecal injection of AAV encoding RNF20 (AAV-RNF20) into naive rat indeed resulted in allodynia in naive rats $(4.47 \pm 0.52 \mathrm{~g}$; one-way ANOVA, $F_{(6,35)}=13.35, p<0.0001, n=6$; Fig. $6 B$ ) that was temporally concordant with RNF20 expression. These data indicated that our protocol for gene transfer efficiently produced robust and sustained RNF20 expression in dorsal horn and resulted in profound pain hypersensitivity. To further test whether spinal RNF20/H2Bub/pRNAPll/mGluR5 transcription axis forms and works in pain, we next intrathecally injected RNF20 siRNA and $\alpha$-amanitin into RNF20-transferred rats. Intriguingly, RNF20 siRNA ( $5 \mu \mathrm{g}, 10 \mu \mathrm{l}$, daily from days 11-14 after

\footnotetext{
$\leftarrow$

(Figure legend continued.) to GAPDH) demonstrating that SNL-enhanced phosphorylated RNAPII (pRNAPII) expression in the ipsilateral dorsal horn was attenuated by administration of RNF20 siRNA (SNL 7D + RNF20 siRNA, $5 \mu \mathrm{g}, 10 \mu \mathrm{l}$, daily from days 3- 6 after SNL operation). MS siRNA, Missense siRNA; IB, immunoblotting. ${ }^{* *} p<0.01$ versus Sham 7D. ${ }^{\# \#} p<0.01$ versus SNL 7D. C, Intrathecal RNF20 siRNA (SNL 7D+RNF20 siRNA, $10 \mu \mathrm{l}, 5 \mu \mathrm{g}$ ) inhibited SNLenhanced $m G / u R 5$ promoter fragments immunoprecipitated by pRNAPII-specific antibodies. ${ }^{* *} p<0.01$ versus Sham 7D. ${ }^{\#} p<0.05$ versus SNL 7D. D, Intrathecal MPEP (a mGluR5 antagonist, SNL 7D+MPEPs, $10 \mu \mathrm{l}, 300 \mathrm{~nm}$, daily from days 3-6 after SNL operation) inhibited SNL-enhanced expression of mGluR5, but not RNF20, H2Bub, or pRNAPII, in the ipsilateral dorsal horn. ${ }^{* *} p<0.01$ versus Sham 7D. ${ }^{\# \#} p<0.01$ versus SNL 7D. E, Intrathecal $\alpha$-amanitin (SNL $7 \mathrm{D}+\alpha$-amanitin, an inhibitor of RNAPII; $300 \mathrm{~nm}, 1$ and $3 \mu \mathrm{m} ; 10 \mu \mathrm{l}$; daily from days $3-6$ after SNL) dose-dependently increased the ipsilateral paw withdrawal threshold of SNL rats. ${ }^{* *} p<$ 0.01 versus Sham 7D. ${ }^{\# \#} p<0.01$ versus SNL 7D. F, G, Intrathecal $\alpha$-amanitin (SNL 7D $+\alpha$ amanitin, an inhibitor of RNAPII; $3 \mu \mathrm{m} ; 10 \mu$ l; daily from days $3-6$ after SNL) inhibited SNLenhanced expression levels of $m G / u R 5$ mRNA and pRNAPII and mGluR5, but not RNF20 and H2Bub, in the ipsilateral dorsal horn. ${ }^{*} p<0.05$ versus Sham 7D. ${ }^{* *} p<0.01$ versus Sham $7 \mathrm{D}$. ${ }^{\#} p<0.05$ versus SNL 7D. ${ }^{\#} p<0.01$ versus SNL 7D. $\boldsymbol{H}$, Intrathecal $\alpha$-amanitin (SNL 7D $+\alpha$ amanitin, an inhibitor of RNAPII; $3 \mu \mathrm{m} ; 10 \mu \mathrm{l}$; daily from days $3-6$ after SNL) inhibited SNLenhanced abundance of $m$ GluR5 promoter fragments immunoprecipitated by pRNAPII-specific antibodies, not RNF20 and H2Bub, in the ipsilateral dorsal horn. ${ }^{* *} p<0.01$ versus Sham 7D. $\# p<0.01$ versus SNL 7D.
}

virus injection) and $\alpha$-amanitin ( $3 \mu \mathrm{M}, 10 \mu \mathrm{l}$, daily from days 11-14 after virus injection) markedly reversed AAV-RNF20induced allodynia in naive rat (from $4.47 \pm 0.52 \mathrm{~g}$ to $10.20 \pm$ $0.54 \mathrm{~g}$ and $9.65 \pm 0.90 \mathrm{~g}$; Fig. $6 B$ ). RT-PCR and Western blot analyses revealed that AAV-RNF20 increased the mRNA and protein expression levels of mGluR5, RNF20, H2Bub, and pRNAPII in the ipsilateral dorsal horn $(2.19 \pm 0.13,0.25 \pm 0.01$, $0.24 \pm 0.01,0.37 \pm 0.01$, and $0.47 \pm 0.04)$, which were markedly inhibited by RNF20 siRNA ( $5 \mu \mathrm{g}, 10 \mu \mathrm{l} ; 1.15 \pm 0.10,0.12 \pm 0.01$, $0.15 \pm 0.01,0.18 \pm 0.01$, and $0.21 \pm 0.01$; Fig. $6 C, D)$. Intrathecally injected $\alpha$-amanitin ( $3 \mu \mathrm{M}, 10 \mu \mathrm{l})$ into RNF20-transferred rats reversed AAV-RNF20-increased mGluR5 mRNA, mGluR5, and pRNAPII expression $(1.35 \pm 0.08,0.13 \pm 0.01$, and $0.17 \pm$ 0.01 ), but not RNF20 or H2Bub expression, in the ipsilateral dorsal horn in naive rat (mGluR5 mRNA, one-way ANOVA, $F_{(6,28)}=$ 43.05, $p<0.0001, n=5$; RNF20, one-way ANOVA, $F_{(6,28)}=10.57$, $p<0.0001, n=5$; H2Bub, one-way ANOVA, $F_{(6,28)}=20.77, p<$ $0.0001, n=5$; pRNAPII, one-way ANOVA, $F_{(6,28)}=38.34$, $p<0.0001, n=5$; mGluR5, one-way ANOVA, $F_{(6,28)}=17.42, p<$ $0.0001, n=5$; Fig. $6 C, D)$. Moreover, ChIP-qPCR consistently demonstrated that AAV-RNF20 increased the amounts of RNF20, $\mathrm{H} 2 \mathrm{Bub}$, and pRNAPII antibody-recognized $m$ GluR5 promoter fragments in the ipsilateral dorsal horn samples $(0.07 \pm 0.01,1.84 \pm$ 0.13 , and $4.97 \pm 0.24)$; these effects were reversed by treating the SNL animals with RNF20 siRNA ( $5 \mu \mathrm{g}, 10 \mu \mathrm{l} ; 0.03 \pm 0.01,1.29 \pm$ 0.11 , and $3.26 \pm 0.15$; Fig. $6 E$ ). Intrathecally injected $\alpha$-amanitin (3 $\mu \mathrm{M}, 10 \mu \mathrm{l}$ ) into RNF20-transferred rats reversed AAV-RNF20increased amounts of pRNAPII antibody-recognized $m G l u R 5$ promoter fragments $(2.76 \pm 0.18)$, but not RNF20 and H2Bub, in the ipsilateral dorsal horn samples (RNF20, one-way ANOVA, $F_{(6,28)}=$ 8.042, $p<0.0001, n=5$; H2Bub, one-way ANOVA, $F_{(6,28)}=9.472$, $p<0.0001, n=5$; pRNAPII, one-way ANOVA, $F_{(6,28)}=37.15, p<$ $0.0001, n=5$; Fig. $6 E$ ). Collectively, these data provide direct evidence to support spinal RNF20/H2Bub/pRNAPll/mGluR5 signaling pathway involved in the pathogenesis of pain development. TNF- $\alpha$-neutralizing antibody relieves SNL-induced allodynia
via impeding the spinal RNF20/H2Bub/pRNAPII/mGluR5
signaling
Our laboratory has recently demonstrated that TNF- $\alpha$ induces transcription/expression of pain-associated genes by activating RNAPII phosphorylation (Hsieh et al., 2017a) and spinal TNF- $\alpha$ contributes to neuropathic pain pathology by upregulating glutamatergic receptors via protein ubiquitination and degradation (Lin et al., 2015b). To determine whether TNF- $\alpha$ participates in neuropathic pain development via spinal RNF20/H2Bub/pRNAPII/ mGluR5 signaling, we first examined whether loss of TNF- $\alpha$ function in SNL rats results in a corresponding change in behavioral pain. As expected, intrathecal injections of TNF- $\alpha$-neutralizing antibody (100 ng, $10 \mu \mathrm{l}$; daily from days 3-6 after SNL), but not nonspecific IgG (100 ng, $10 \mu \mathrm{l})$, increased the ipsilateral paw withdrawal threshold of SNL rats (from $2.18 \pm 0.43 \mathrm{~g}$ to $7.43 \pm 1.19 \mathrm{~g}$; one-way ANOVA, $F_{(3,20)}=30.87, p<0.0001, n=6$; Fig. $\left.7 A\right)$. Interestingly, TNF- $\alpha$-neutralizing antibody (100 ng, $10 \mu$; daily from days 3-6 after SNL) significantly decreased the SNL-enhanced abundance of mGluR5 mRNA and protein in the ipsilateral dorsal horn samples (from $3.13 \pm 0.26$ to $1.86 \pm 0.12$ and from $0.27 \pm 0.02$ to $0.14 \pm$ 0.01 ; mRNA, one-way ANOVA, $F_{(3,16)}=22.49, p<0.0001, n=5$; protein, one-way ANOVA, $F_{(3,16)}=13.88, p=0.0001, n=5$; Fig. $7 B, C)$. Moreover, intrathecal injection of TNF- $\alpha$-neutralizing antibody (100 ng, $10 \mu \mathrm{l}$; daily from days 3-6 after SNL) into SNLtreated rats significantly decreased RNF20, H2Bub, and pRNAPII antibody-recognized $m G l u R 5$ promoter fragments in the ipsilateral 
A
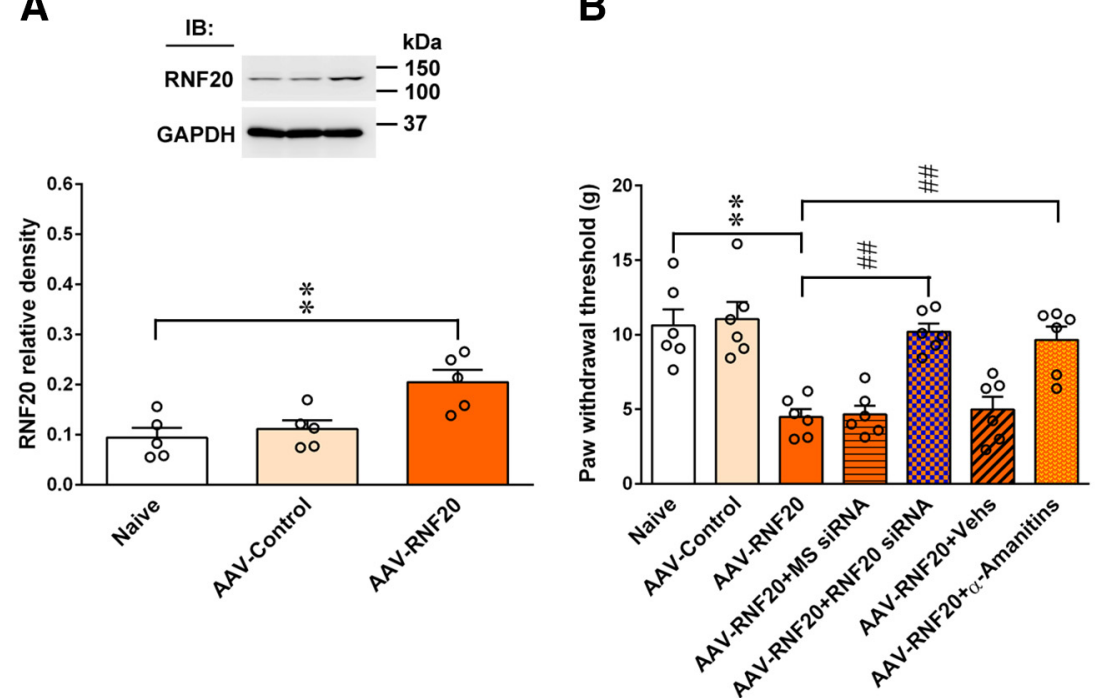

B
C

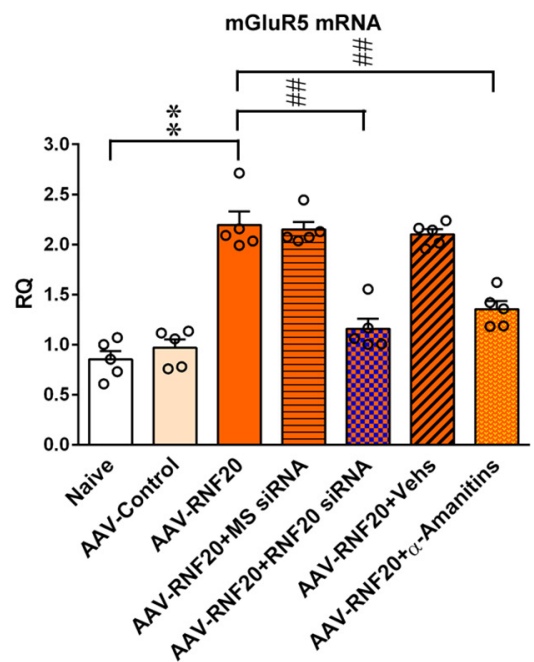

D

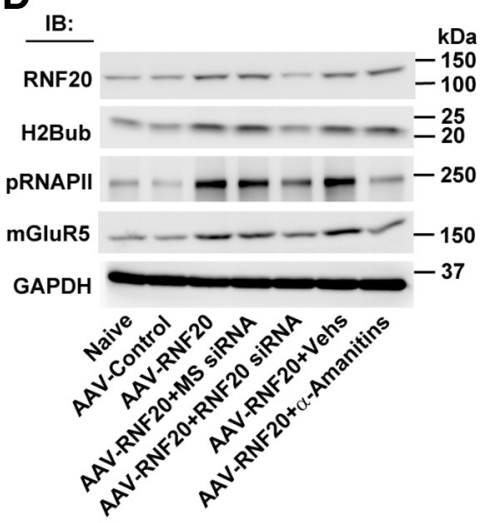

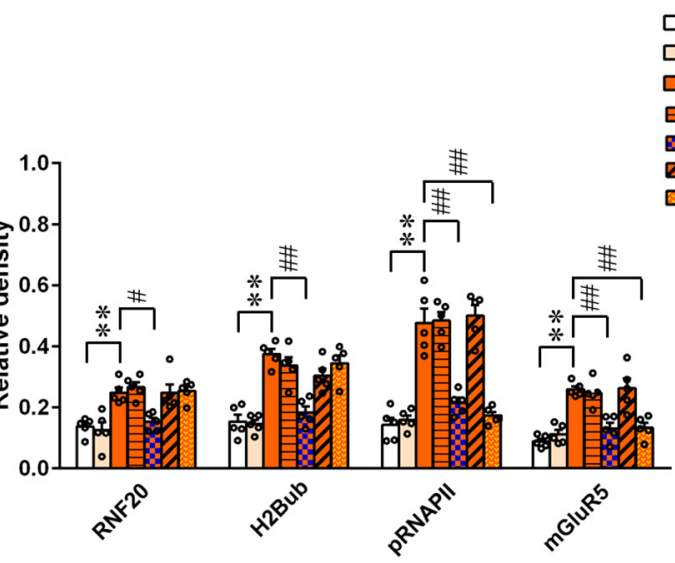

E

ChIP-qPCR

mGluR5 promoter

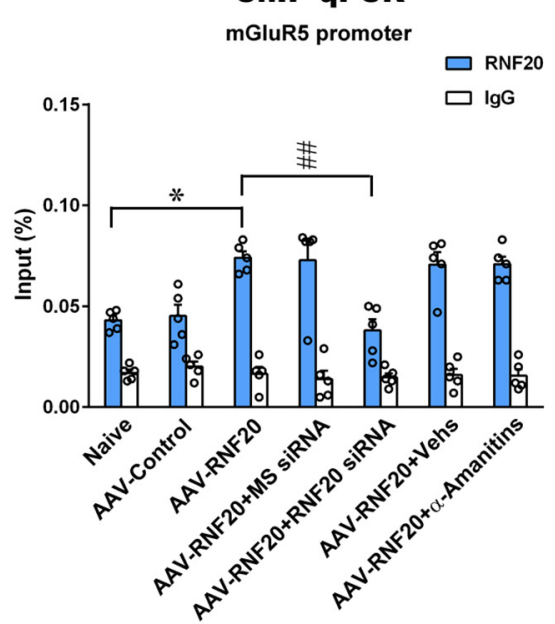

ChIP-qPCR

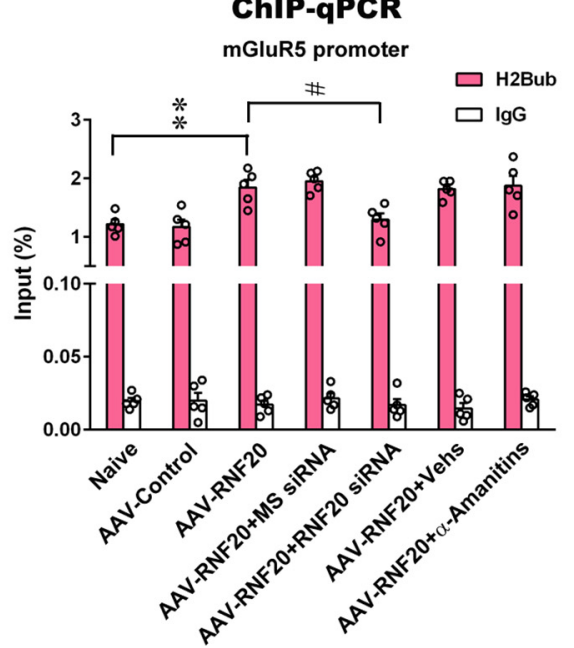

ChIP-qPCR

mGluR5 promoter $\square$ PRNAPII

萧 $\square \operatorname{lgg}$

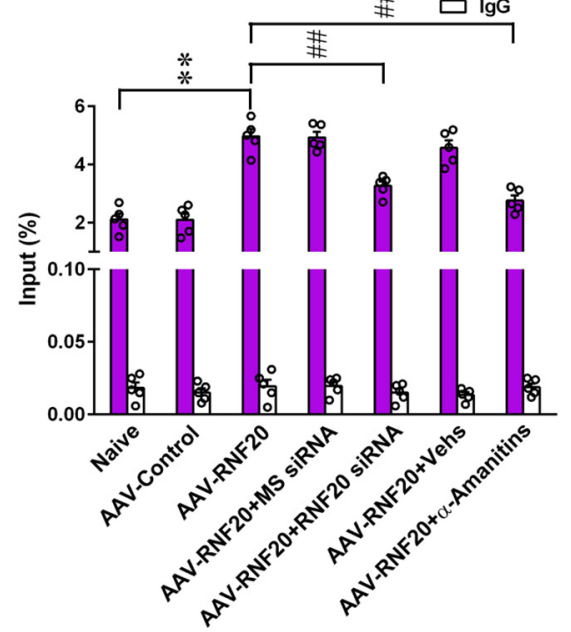

Figure 6. Effects of RNF20 gene transfer on pain-associated behavior and spinal RNF20/H2Bub/pRNAPII/mGluR5 signaling pathway. $A$, Representative Western blot and statistical analyses (normalized to GAPDH) demonstrating AAV-RNF20 increased RNF20 expression in the ipsilateral dorsal horn on day 14 after virus injection. IB, Immunoblotting. ${ }^{* *} p<0.01$ versus Naive. $B, A A V-R N F 20$ significantly decreased the ipsilateral paw withdrawal threshold of the naive group, these effects were reversed by treating the AAV-RNF20 animals with RNF20 siRNA (AAVRNF20 + RNF20 siRNA, $10 \mu \mathrm{l}, 5 \mu \mathrm{g}$; daily from days 11-14 after virus injection) or $\alpha$-amanitin (AAV-RNF20 $+\alpha$-amanitin; an inhibitor of RNAPIl; $3 \mu$ m; $10 \mu l$; daily from days $11-14$ after virus injection). ${ }^{* *} p<0.01$ versus naive. ${ }^{\# \#} p<0.01$ versus AAV-RNF20.C, AAV-RNF20 significantly increased the mGluR5 mRNA in the ipsilateral dorsal horn, these effects were reversed by treating the AAV-RNF20 animals with RNF20 siRNA (AAV-RNF20 + RNF20 siRNA, $10 \mu \mathrm{l}, 5 \mu \mathrm{g}$; daily from days 11-14 after virus injection) or $\alpha$-amanitin (AAV-RNF20 + $\alpha$-amanitin; an inhibitor of RNAPIl; $3 \mu$ m; $10 \mu$; daily from days 11-14 after virus injection). D, AAV-RNF20 significantly increased the expression of RNF20, H2Bub, pRNAPII, and mGluR5 in the ipsilateral dorsal horn, these effects were reversed by treating the AAV-RNF20 animals with RNF20 siRNA (AAV-RNF20+RNF20 siRNA, $10 \mu \mathrm{l}, 5 \mu \mathrm{g}$; daily from days 11-14 after virus injection). Intrathecal (Figure legend continues.) 
A

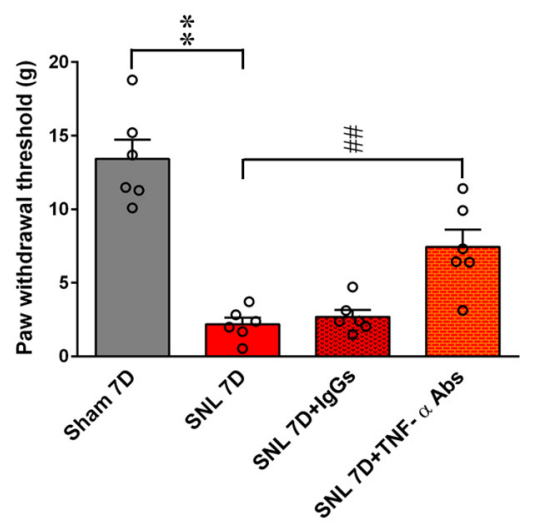

D

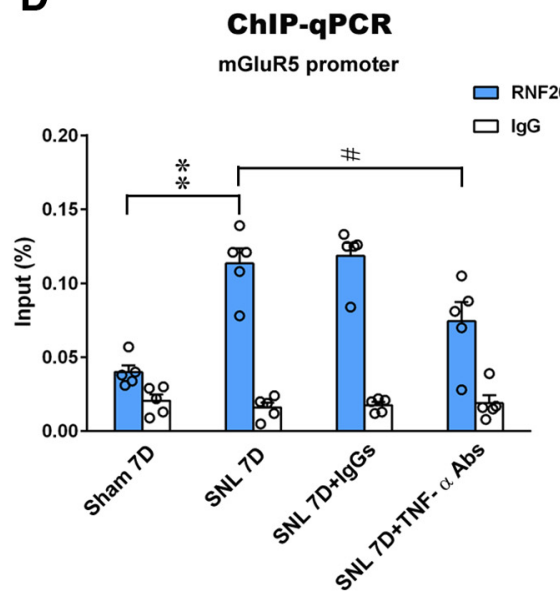

B

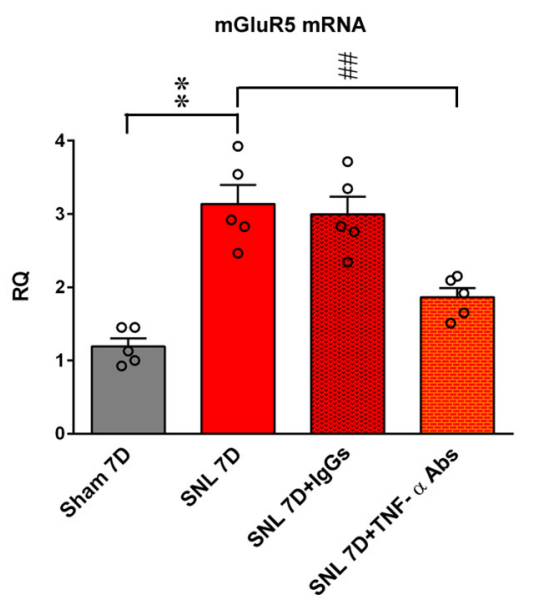

ChIP-qPCR

mGluR5 promoter

C
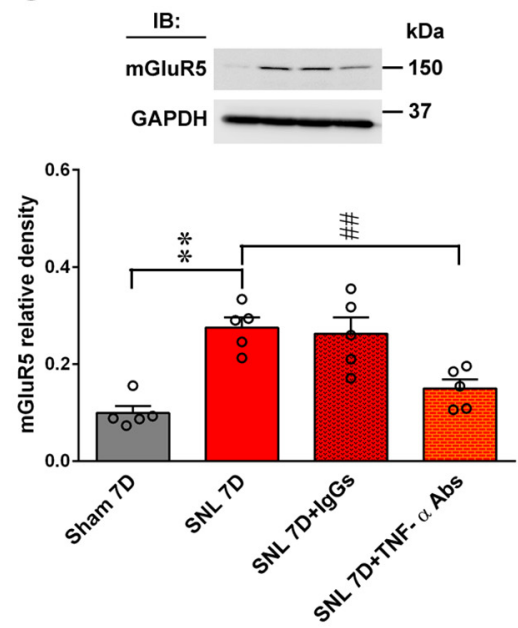

ChIP-qPCR

mGluR5 promoter

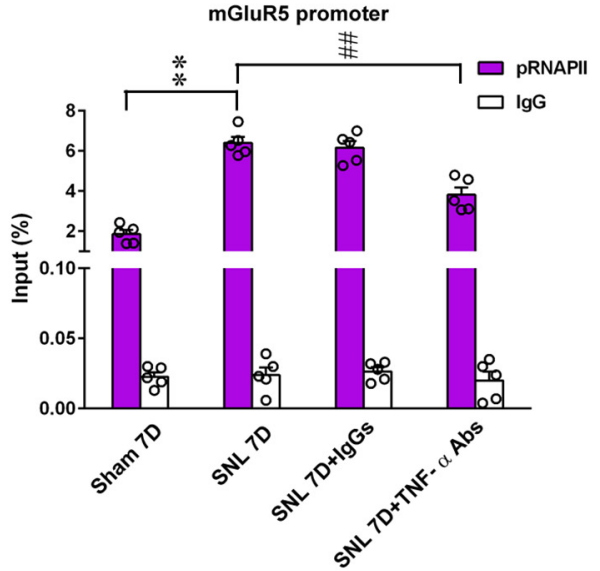

Figure 7. TNF- $\alpha$-neutralizing antibody relieves SNL-induced allodynia by attenuating spinal RNF20/H2Bub/pRNAPII/mGluR5 signaling. $\boldsymbol{A}$, Intrathecal administration of TNF- $\alpha$-neutralizing antibody (SNL7D + TNF- $\alpha$ Abs, $100 \mathrm{ng}, 10 \mu$ l; daily from days 3-6 after SNL), but not nonspecific lgG (SNL 7D+lgGs, $100 \mathrm{ng}, 10 \mu$ ), increased the ipsilateral paw withdrawal threshold of SNL rats (one-way ANOVA, $F_{(3,20)}=30.87, p<0.0001, n=6$ ). ${ }^{* *} p<0.01$ versus Sham 7D. ${ }^{\# \#} p<0.01$ versus SNL 7D. B, C, Intrathecal administration of TNF- $\alpha$-neutralizing antibody (SNL 7D+TNF- $\alpha$ Abs, $100 \mathrm{ng}, 10 \mu$; daily from days $3-6$ after $S N L)$ reversed the expression levels of mGluR5 mRNA and protein in the dorsal horn of SNL rats (mRNA, one-way ANOVA, $F_{(3,16)}=22.49, p<0.0001$, $n=5$; protein, one-way ANOVA, $F_{(3,16)}=13.88, p=0.0001, n=5$ ). IB, Immunoblotting. ${ }^{* *} p<0.01$ versus Sham 7D. ${ }^{\# \#} p<0.01$ versus SNL 7D. D, TNF- $\alpha$-neutralizing antibody (SNL 7D + TNF- $\alpha$ Abs, $100 \mathrm{ng}, 10 \mu \mathrm{l}$; daily from days $3-6$ after SNL) inhibited the $m G$ luR5 promoter fragments immunoprecipitated by RNF20-, H2NBub-, and pRNAPII-specific antibodies in the ipsilateral dorsal horn of SNL rats (RNF20, one-way ANOVA, $F_{(3,16)}=14.76, p<0.0001, n=5$; H2Bub, one-way ANOVA, $F_{(3,16)}=17.11, p<0.0001, n=5 ;$ pRNAPII, one-way ANOVA, $F_{(3,16)}=50.07, p<0.0001$, $n=5) .{ }^{* *} p<0.01$ versus Sham 7D. ${ }^{\#} p<0.05$, versus SNL 7D. ${ }^{\#} p<0.01$ versus SNL 7D.

dorsal horn samples (from $0.11 \pm 0.01$ to $0.07 \pm 0.01$, from $2.34 \pm$ 0.24 to $1.43 \pm 0.12$, and from $6.40 \pm 0.29$ to $3.82 \pm 0.36, n=5 ; \mathrm{RNF} 20$, one-way ANOVA, $F_{(3,16)}=14.76, p<0.0001, n=5 ; \mathrm{H} 2 \mathrm{Bub}$, one-way ANOVA, $F_{(3,16)}=17.11, p<0.0001, n=5$; pRNAPII, one-way ANOVA, $F_{(3,16)}=50.07, p<0.0001, n=5$; Fig. 7D). These observa-

$\leftarrow$

(Figure legend continued.) $\quad \alpha$-amanitin (AAV-RNF20 $+\alpha$-amanitin, an inhibitor of RNAPIl; 3 $\mu \mathrm{M} ; 10 \mu \mathrm{l}$; daily from days $11-14$ after virus injection) inhibited AAV-RNF20-enhanced expression levels of pRNAPII and mGluR5, but not RNF20 and H2Bub, in the ipsilateral dorsal horn. ${ }^{* *} p<0.01$ versus Naive. ${ }^{\#} p<0.05$ versus AAV-RNF20. ${ }^{\# \#} p<0.01$ versus AAV-RNF20. $\boldsymbol{E}$, AAV-RNF20 significantly increased the $m$ GluR5 promoter fragments immunoprecipitated by RNF20-, H2Bub-, and pRNAPII-specific antibodies in the ipsilateral dorsal horn, these effects were reversed by treating the AAV-RNF20 animals with RNF20 siRNA (AAV-RNF20+RNF20 siRNA, $10 \mu \mathrm{l}, 5 \mu \mathrm{g}$ daily from days $11-14$ after virus injection). Intrathecal $\alpha$-amanitin (AAVRNF20 $+\alpha$-amanitin, an inhibitor of RNAPII; $3 \mu \mathrm{m} ; 10 \mu$ l; daily from days $11-14$ after virus injection) inhibited AAV-RNF20-increased the $m G / u R 5$ promoter fragments immunoprecipitated by pRNAPII-specific antibodies, but not RNF20 and H2Bub, in the ipsilateral dorsal horn ${ }^{*} p<0.05$ versus Naive. ${ }^{* *} p<0.01$ versus Naive. ${ }^{\#} p<0.05$ versus AAV-RNF20. ${ }^{\# \#} p<0.01$ versus AAV-RNF20. tions indicate that TNF- $\alpha$-neutralizing antibody ameliorates SNLinduced behavioral allodynia by impeding the spinal RNF20/H2Bub/ pRNAPII/mGluR5 signaling cascade.

\section{TNF- $\alpha$ triggers RNF20/H2Bub/pRNAPII/mGluR5 signaling} in the dorsal horn after SNL

Next, to further confirm the hypothesis that spinal TNF- $\alpha$ contributes to the development of neuropathic pain through activation of RNF20/H2Bub/pRNAPII/mGluR5, we injected recombinant TNF- $\alpha$ into naive rats. Quite similar to the SNL, spinal TNF- $\alpha$ administration ( $1 \mathrm{pm}, 10 \mu \mathrm{l}$, once daily for $4 \mathrm{~d}$ ) induced behavioral allodynia (from $12.34 \pm 1.57 \mathrm{~g}$ to $3.30 \pm 0.83 \mathrm{~g}, n=6$ ) that was inhibited by RNF20 siRNA ( $5 \mu \mathrm{g}, 10 \mu \mathrm{l}$, once daily for $4 \mathrm{~d} ; 8.89 \pm$ $1.11 \mathrm{~g}$; one-way ANOVA, $F_{(4,25)}=14.12, p<0.0001, n=6$; Fig. $8 A$ ). TNF- $\alpha$ injection ( $1 \mathrm{pM}, 10 \mu \mathrm{l}$, once daily for $4 \mathrm{~d}$ ) also significantly increased the abundance of mGluR5 mRNA and protein (from $1.01 \pm 0.10$ to $2.52 \pm 0.23$ and from $0.10 \pm 0.02$ to $0.26 \pm 0.03, n=$ 5 ) as well as $m G l u R 5$ promoter fragments immunoprecipitated by RNF20-, H2Bub-, and pRNAPII-specific antibodies in the ipsilateral 
A

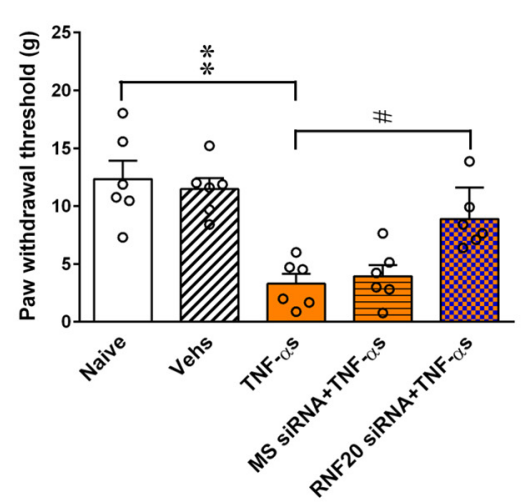

D

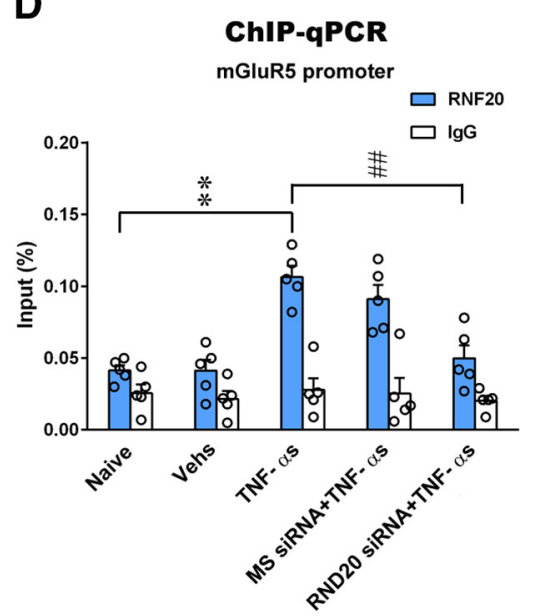

B
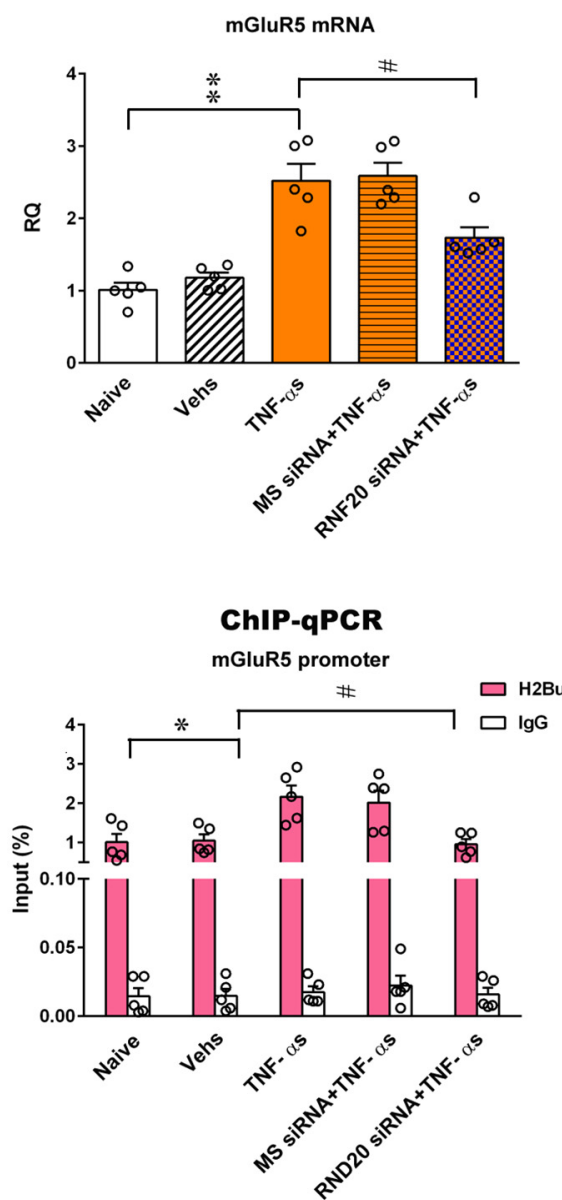
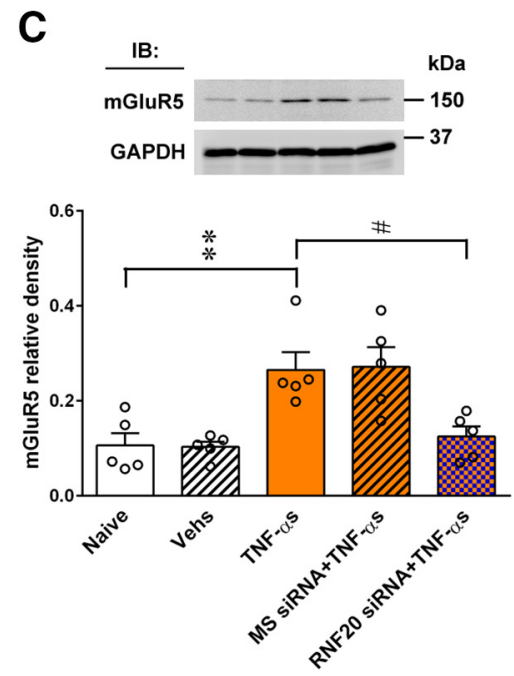

ChIP-qPCR

mGluR5 promoter

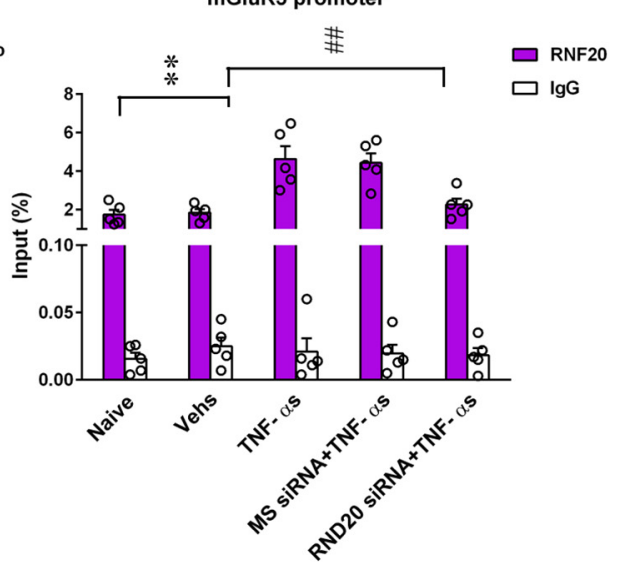

Figure 8. TNF- $\alpha$ induces allodynia via RNF20/H2Bub/pRNAPII/mGluR5 signaling in the dorsal horn. $A$, TNF- $\alpha(1 \mathrm{pM}, 10 \mu \mathrm{l}$, once daily for $4 \mathrm{~d})$-decreased paw withdrawal latency was ameliorated by RNF20 siRNA (RNF20 siRNA + TNF- $\alpha, 5 \mu \mathrm{g}, 10 \mu$ l, once daily for $4 \mathrm{~d}$; one-way ANOVA, $\left.F_{(4,25)}=14.12, p<0.0001, n=6\right)$. ${ }^{* *} p<0.01$ versus Naive. ${ }^{\#} p<0.05$ versus TNF- $\alpha$. $B, C$, TNF- $\alpha(1$ pм, $10 \mu \mathrm{l}$, once daily for $4 \mathrm{~d}$ )-enhanced mGluR5 mRNA and protein expression levels in the dorsal horn were attenuated by RNF20 siRNA (RNF20 siRNAi + TNF- $\alpha, 5 \mu \mathrm{g}$, $10 \mu \mathrm{l}$, once daily for $4 \mathrm{~d}$; mRNA, one-way ANOVA, $F_{(4,20)}=21.72, p<0.0001, n=5$; protein, one-way ANOVA, $\left.F_{(4,20)}=8.476, p=0.0004, n=5\right) .{ }^{* *} p<0.01$ versus Naive. ${ }^{\#} p<0.05$ versus TNF- $\alpha$. D, Intrathecal administration of RNF20 siRNA (RNF20 siRNA + TNF- $\alpha, 5 \mu \mathrm{g}, 10 \mu \mathrm{l}$, once daily for $4 \mathrm{~d}$ ) inhibited TNF- $\alpha$ (1 pm, $10 \mu \mathrm{l}$, once daily for $4 \mathrm{~d}$ )-increased $m G$ luR5 promoter fragments immunoprecipitated by RNF20-, H2Bub-, and pRNAPII-specific antibodies (RNF20, one-way ANOVA, $F_{(4,20)}=14.94, p<0.0001, n=5$; H2NBub, one-way ANOVA, $F_{(4,20)}=6.810, p=0.0013, n=5$; pRNAPII, one-way ANOVA, $\left.F_{(4,20)}=11.60, p<0.0001, n=5\right) .{ }^{*} p<0.05$ versus Naive. ${ }^{* *} p<0.01$ versus Naive. ${ }^{\#} p<0.05$ versus TNF- $\alpha .{ }^{\# \#} p<0.01$ versus TNF- $\alpha$.

dorsal horn (from $0.041 \pm 0.01$ to $0.10 \pm 0.01$, from $1.01 \pm 0.21$ to $2.16 \pm 0.28$, and from $1.74 \pm 0.24$ to $4.63 \pm 0.67, n=5$ ); these effects were reversed by RNF20 siRNA ( $5 \mu \mathrm{g}, 10 \mu$ l, once daily for $4 \mathrm{~d}$; $1.73 \pm 0.14,0.12 \pm 0.02,0.049 \pm 0.01,0.95 \pm 0.12$, and $2.26 \pm 0.30$; mRNA, one-way ANOVA, $F_{(4,20)}=21.72, p<0.0001$, $n=5$; protein, one-way ANOVA, $F_{(4,20)}=8.476, p=0.0004, n=5$; RNF20, one-way ANOVA, $F_{(4,20)}=14.94, p<0.0001, n=5$; H2NBub, one-way ANOVA, $F_{(4,20)}=6.810, p=0.0013, n=$ 5; pRNAPII, one-way ANOVA, $F_{(4,20)}=11.60, p<0.0001, n=5$; Fig. $8 B-D$ ). These results provide pharmacological evidence supporting the role of TNF- $\alpha$ in SNL-induced neuropathic pain, potentially via RNF20/H2Bub/pRNAPII-dependent modification of the transcription/expression of $m G l u R 5$ in the ipsilateral dorsal horn neurons.

\section{Discussion}

In the current study, we reported a novel function of the RNF20dependent $\mathrm{H} 2 \mathrm{Bub}$ transcriptional axis in the dorsal horn, which plays a crucial role in the pathogenesis of neuropathic pain development. Our detailed analyses revealed that, following SNL, RNF20 ubiquitinizes histone H2B to phosphorylate RNAPII, which couples pRNAPII to the $m G l u R 5$ promoter and facilitates transcription of $m G l u R 5$ in the dorsal horn. Concordantly, all these changes caused by SNL were reversed by focal knockdown of spinal RNF20 expression. Moreover, by intrathecally injecting TNF- $\alpha$ into naive animals and TNF- $\alpha$-specific neutralizing antibodies into SNL-treated animals, we further validated that TNF- $\alpha$ activates the RNF20/H2Bub/pRNAPII transcriptional axis in the dorsal horn and promotes $m G l u R 5$ transcription to support the development of neuropathic pain. To the best of our knowledge, results of the present study first show that histone monoubiquitylation, an epigenetic post-translational modification, upregulates spinal mGluR5 expression to support the development of neuropathic pain. Our findings provide a novel insight into the spinal mechanism mediating pain 
hypersensitivity, thereby indicating a possible medical strategy for neuropathic relief by targeting the spinal RNF20/ H2Bub/pRNAPII/mGluR5 signaling pathway.

H2B is expressed in neuron (Ouyang et al., 2015), astrocyte (McCullough et al., 2012), and microglia (Yun et al., 2011); and $\mathrm{H} 2 \mathrm{~B}$ ubiquitination is linked to epigenetic modification of cell activity in both neuron (Ouyang et al., 2015) and glia (McCullough et al., 2012). In the current study, immunohistochemistry image reveals the SNL-enhanced H2Bub immunoreactivity in the ipsilateral dorsal horn localized coincident mainly, but not exclusively, with neuronal marker. Nevertheless, although the immunoreactivity is relatively minor, the SNL-enhanced $\mathrm{H} 2 \mathrm{Bub}$ immunoreactivity also colocalized with astrocyte and microglia markers. For studies that have linked mGluR5-dependent plasticity that occurs in neuron (Lin et al., 2015a), astrocyte (Narita et al., 2005), and microglia (Byrnes et al., 2009), we propose the RNF20/H2Bub/pRNAPII/mGluR5 cascade not only in dorsal horn neurons but also in astrocyte and microglia contributes to the pain-associated spinal plasticity. Yet, the precise contribution of each cell needs further studies to be clarified.

RNF20 is a major E3 ligase responsible for the monoubiquitination of histone H2B (Kim et al., 2005; Zhu et al., 2005), which is actively engaged in ongoing transcription (Minsky et al., 2008). In the current study, SNL increased RNF20 expression, H2B monoubiquitination, and enhanced RNF20-H2Bub interaction in the ipsilateral dorsal horn, which was accompanied by behavioral allodynia (Fig. 8). Conversely, focal knockdown of spinal RNF20 expression markedly ameliorated established allodynia and suppressed RNF20 expression, H2B ubiquitination, and RNF20-H2Bub interaction observed in SNL rats. Consistent with evidence obtained from mouse embryonic and dermal fibroblasts showing a decrement in RNF20 expression that consequently led to a reduction in H2Bub levels (Blank et al., 2012), our data support the role of RNF20-dependent H2B ubiquitination in the spinal machinery underlying neuropathic pain development. Nevertheless, in the current study, SNL-enhanced spinal H2Bub expression was not completely eliminated by knockdown of RNF20 expression. Although the detailed mechanism remains unclear, these data suggest that RNF20 is not the sole player mediating $\mathrm{H} 2 \mathrm{~B}$ ubiquitination. Interestingly, in a study investigating H2Bub-dependent antitumorigenic effects, RNF20 and RNF40 bound discrete, but closely located, residues required for the maintenance of $\mathrm{H} 2 \mathrm{~B}$ monoubiquitination (Hahn et al., 2012). In cultured HeLa cells, H2B monoubiquitination is performed by the orthologous heteromeric RNF20/RNF40 complex (Kim et al., 2005; Zhu et al., 2005). Thus, whether RNF20 cooperates with other RNF families, such as RNF40 or other molecules to induce $\mathrm{H} 2 \mathrm{~B}$ ubiquitination, and contributes to the spinal plasticity underlying neuropathic pain development is an interesting question that needs to be investigated in the future. Moreover, in 293T cells, RNF20 depletion decreases mRNA expression levels of growth arrest and DNA-damage-inducible protein $45 \beta$ (Gadd45b) (Zhang et al., 2011). One of our recent publications has linked spinal Gadd45b to neuropathic pain pathophysiology (Lai et al., 2017); the possibility that the RNF20-H2Bub pathway contributes to neuropathic pain development through modifying Gadd45b expression in the dorsal horn warrants further study.

In agreement with studies linking $\mathrm{H} 2 \mathrm{Bub}$ to forms of activitydependent plasticity in brain regions (Bach et al., 2015), the current study revealed that RNF20-dependent H2Bub mechanisms participate in the spinal plasticity underlying the pathophysiology of behavioral allodynia caused by neuropathic pain. Our findings are supported by a work investigating nociceptive hypersensitivity mechanisms, which suggests that nociceptive-associated plasticity in spinal levels relies on molecular processes similar to those underlying associative learning in certain brain regions, particularly in the hippocampus (Ji et al., 2003). However, the potential involvement of other RNF families in the pathology underlying pain hypersensitivity cannot be ruled out because RNF8 deficiency causes pathological neuronal degeneration in pyramidal neurons and cognitive deficits (Ouyang et al., 2015).

In addition to histone $\mathrm{H} 2 \mathrm{~A}$ ubiquitination at Lys119, monoubiquitination of H2B is the best-studied case (Fuchs et al., 2014). H2B undergoes ubiquitination at Lys 34, 120, and 123 (Wu et al., 2011; Fuchs et al., 2014). Because H2Bub occurs at Lys123 in yeast and at Lys120 in mammals (Kim and Roeder, 2011), and H2B monoubiquitination at Lys 120 dynamically regulates synaptic plasticity (Bach et al., 2015), we investigated the role of $\mathrm{H} 2 \mathrm{Bub}$ in the spinal plasticity underlying SNL-induced neuropathic pain by focusing on H2B ubiquitination at Lys120. However, the possible role of $\mathrm{H} 2 \mathrm{~B}$ ubiquitination at residues other than Lys sites cannot be excluded.

In the current study, by intrathecally administering TNF- $\alpha$ to naive animals and TNF- $\alpha$-specific neutralizing antibodies to SNL animals, we validated that TNF- $\alpha$ activates the RNF20/H2Bub/ pRNAPII transcriptional axis in the dorsal horn and consequently promotes mGluR5 transcription to support the development of neuropathic allodynia. This finding is consistent with our previous studies demonstrating that spinal TNF- $\alpha$ contributes to the development of neuropathic pain by upregulating glutamate receptors via modifying protein ubiquitination and degradation (Lin et al., 2015b), and TNF- $\alpha$ epigenetically modifies pain-associated gene transcription to support inflammatory hyperalgesia by activating RNAPII phosphorylation (Hsieh et al., 2017a). Nevertheless, a study investigating inflammationassociated tumorigenesis has shown that TNF- $\alpha$ depletes RNF20 and hence impedes $\mathrm{H} 2 \mathrm{~B}$ monoubiquitination to upregulate a panel of inflammation-associated genes (Tarcic et al., 2016). Although the detailed mechanism is unclear, several potential causes might underlie this discrepancy. First, by contrast to our study investigating the RNF20-H2Bub transcriptional axis in dorsal horn of in vivo preparations, Tarcic et al. (2016) inspected mammary epithelial MCF10A cells in culture. We speculate that various cell types or transcription activity could result in different gene expression profiles. Our hypothesis is supported by findings showing that $\mathrm{H} 2 \mathrm{Bub}$ is mainly located downstream of transcription start sites and preferentially associates with highly transcribed genes (Minsky et al., 2008); however, H2Bub can also negatively regulate transcription and may contribute to heterochromatin silencing (Zhang et al., 2008). Moreover, in HeLa cells, depletion of RNF20 results in decreased H2B ubiquitination with upregulation of some proto-oncogenes accompanied by downregulation of the p53 tumor suppressor gene (Shema et al., 2011). Nevertheless, the detailed mechanism underlying this inconsistency requires further study.

RNAPII-dependent transcription is accompanied by a conserved pattern of histone modifications that regulate gene expression (Mbogning et al., 2015). The activity of the H2Bubiquitylation machinery is regulated by interactions with the transcriptional apparatus, including RNAP II (Xiao et al., 2005). After phosphorylation of Ser2 within the RNAPII CTD, RNF20-mediated $\mathrm{H} 2 \mathrm{~B}$ monoubiquitination promotes the transcriptional elongation of targeted genes (Wu et al., 2014). Moreover, our recent study shows that phosphorylation of ser2 of RNAPII promotes transcriptional elongation of tar- 
geted genes to mediate pain hyperalgesia (Hsieh et al., 2017a). Consistently, in the current study, we investigated the epigenetic mechanism underlying nociceptive sensitization using a selective antibody against pSer2 of RNAPII, and SNLenhanced $\mathrm{H} 2 \mathrm{Bub}$ expression induced Ser2 phosphorylation in the CTD of RNAPII, indicating the contribution of phosphorylation of Ser2 of RNAP II to the RNF20/H2Bub-dependent epigenetic machinery underlying neuropathic pain-associated spinal plasticity. However, because phosphorylation of RNAPII primarily occurs at the Ser 2 and Ser 5 residues of the CTD (Phatnani and Greenleaf, 2006), the potential roles of Ser5 phosphorylation in this machinery cannot be excluded because Ser2 and Ser5 work cooperatively in gene activation (Ahn et al., 2004); additionally, H2Bub specifically associates with pSer5 of RNAPII, which is committed to elongation (Xiao et al., 2005).

\section{References}

Ahn SH, Kim M, Buratowski S (2004) Phosphorylation of serine 2 within the RNA polymerase II C-terminal domain couples transcription and $3^{\prime}$ end processing. Mol Cell 13:67-76. CrossRef Medline

Alpi AF, Patel KJ (2009) Monoubiquitylation in the fanconi anemia DNA damage response pathway. DNA Repair (Amst) 8:430-435. CrossRef Medline

Bach SV, Tacon PR, Morgan JW, Hegde AN (2015) Proteasome regulates transcription-favoring histone methylation, acetylation and ubiquitination in long-term synaptic plasticity. Neurosci Lett 591:59-64. CrossRef Medline

Berger SL (2007) The complex language of chromatin regulation during transcription. Nature 447:407-412. CrossRef Medline

Blank M, Tang Y, Yamashita M, Burkett SS, Cheng SY, Zhang YE (2012) A tumor suppressor function of Smurf2 associated with controlling chromatin landscape and genome stability through RNF20. Nat Med 18:227234. CrossRef Medline

Byrnes KR, Stoica B, Riccio A, Pajoohesh-Ganji A, Loane DJ, Faden AI (2009) Activation of metabotropic glutamate receptor 5 improves recovery after spinal cord injury in rodents. Ann Neurol 66:63-74. CrossRef Medline

Chaplan SR, Bach FW, Pogrel JW, Chung JM, Yaksh TL (1994) Quantitative assessment of tactile allodynia in the rat paw. J Neurosci Methods 53:5563. CrossRef Medline

Chung JM, Kim HK, Chung K (2004) Segmental spinal nerve ligation model of neuropathic pain. Methods Mol Med 99:35-45. CrossRef Medline

Foglizzo M, Middleton AJ, Day CL (2016) Structure and function of the RING domains of RNF20 and RNF40, dimeric E3 ligases that monoubiquitylate histone H2B. J Mol Biol 428:4073-4086. CrossRef Medline

Fuchs G, Hollander D, Voichek Y, Ast G, Oren M (2014) Cotranscriptional histone $\mathrm{H} 2 \mathrm{~B}$ monoubiquitylation is tightly coupled with RNA polymerase II elongation rate. Genome Res 24:1572-1583. CrossRef Medline

Hahn MA, Dickson KA, Jackson S, Clarkson A, Gill AJ, Marsh DJ (2012) The tumor suppressor $\mathrm{CDC} 73$ interacts with the ring finger proteins RNF20 and RNF40 and is required for the maintenance of histone 2B monoubiquitination. Hum Mol Genet 21:559-568. CrossRef Medline

Hsieh MC, Ho YC, Lai CY, Wang HH, Lee AS, Cheng JK, Chau YP, Peng HY (2017a) Bromodomain-containing protein 4 activates voltage-gated sodium channel 1.7 transcription in dorsal root ganglia neurons to mediate thermal hyperalgesia in rats. Anesthesiology 127:862-877. CrossRef Medline

Hsieh MC, Ho YC, Lai CY, Chou D, Wang HH, Chen GD, Lin TB, Peng HY (2017b) Melatonin impedes Tetl-dependent mGluR5 promoter demethylation to relieve pain. J Pineal Res 63:4. CrossRef Medline

Hwang WW, Venkatasubrahmanyam S, Ianculescu AG, Tong A, Boone C, Madhani HD (2003) A conserved RING finger protein required for histone H2B monoubiquitination and cell size control. Mol Cell 11:261266. CrossRef Medline

Ishino Y, Hayashi Y, Naruse M, Tomita K, Sanbo M, Fuchigami T, Fujiki R, Hirose K, Toyooka Y, Fujimori T, Ikenaka K, Hitoshi S (2014) Brela, a histone $\mathrm{H} 2 \mathrm{~B}$ ubiquitin ligase, regulates the cell cycle and differentiation of neural precursor cells. J Neurosci 34:3067-3078. CrossRef Medline

Ji RR, Kohno T, Moore KA, Woolf CJ (2003) Central sensitization and LTP: do pain and memory share similar mechanisms? Trends Neurosci 26: 696-705. CrossRef Medline

Kim J, Roeder RG (2011) Nucleosomal H2B ubiquitylation with purified factors. Methods 54:331-338. CrossRef Medline

Kim J, Hake SB, Roeder RG (2005) The human homolog of yeast BRE1 functions as a transcriptional coactivator through direct activator interactions. Mol Cell 20:759-770. CrossRef Medline

Kouzarides T (2007) Chromatin modifications and their function. Cell 128: 693-705. CrossRef Medline

Lai CY, Ho YC, Hsieh MC, Wang HH, Cheng JK, Chau YP, Peng HY (2016) Spinal Fbxo3-dependent Fbxl2 ubiquitination of active zone protein RIM1alpha mediates neuropathic allodynia through CaV2.2 activation. J Neurosci 36:9722-9738. CrossRef Medline

Lai CY, Hsieh MC, Ho YC, Lee AS, Wang HH, Cheng JK, Chau YP, Peng HY (2017) Growth arrest and DNA-damage-inducible protein 45betamediated DNA demethylation of voltage-dependent T-type calcium channel 3.2 subunit enhances neuropathic allodynia after nerve injury in rats. Anesthesiology 126:1077-1095. CrossRef Medline

Lin TB, Lai CY, Hsieh MC, Wang HH, Cheng JK, Chau YP, Chen GD, Peng HY (2015a) VPS26A-SNX27 interaction-dependent mGluR5 recycling in dorsal horn neurons mediates neuropathic pain in rats. J Neurosci 35:14943-14955. CrossRef Medline

Lin TB, Hsieh MC, Lai CY, Cheng JK, Chau YP, Ruan T, Chen GD, Peng HY (2015b) Fbxo3-dependent Fbxl2 ubiquitination mediates neuropathic allodynia through the TRAF2/TNIK/GluR1 cascade. J Neurosci 35: 16545-16560. CrossRef Medline

Livak KJ, Schmittgen TD (2001) Analysis of relative gene expression data using real-time quantitative PCR and the 2(-delta delta $\mathrm{C}(\mathrm{T})$ ) method. Methods 25:402-408. CrossRef Medline

Matosin N, Fernandez-Enright F, Lum JS, Newell KA (2017) Shifting towards a model of mGluR5 dysregulation in schizophrenia: consequences for future schizophrenia treatment. Neuropharmacology 115:73-91. CrossRef Medline

Mbogning J, Pagé V, Burston J, Schwenger E, Fisher RP, Schwer B, Shuman S, Tanny JC (2015) Functional interaction of Rpb1 and Spt5 C-terminal domains in co-transcriptional histone modification. Nucleic Acids Res 43:9766-9775. CrossRef Medline

McCullough SD, Xu X, Dent SY, Bekiranov S, Roeder RG, Grant PA (2012) Reelin is a target of polyglutamine expanded ataxin-7 in human spinocerebellar ataxia type 7 (SCA7) astrocytes. Proc Natl Acad Sci U S A 109: 21319-21324. CrossRef Medline

Minsky N, Shema E, Field Y, Schuster M, Segal E, Oren M (2008) Monoubiquitinated $\mathrm{H} 2 \mathrm{~B}$ is associated with the transcribed region of highly expressed genes in human cells. Nat Cell Biol 10:483-488. CrossRef Medline

Mohan RD, Dialynas G, Weake VM, Liu J, Martin-Brown S, Florens L, Washburn MP, Workman JL, Abmayr SM (2014) Loss of drosophila ataxin-7, a SAGA subunit, reduces $\mathrm{H} 2 \mathrm{~B}$ ubiquitination and leads to neural and retinal degeneration. Genes Dev 28:259-272. CrossRef Medline

Napolitano G, Majello B, Licciardo P, Giordano A, Lania L (2000) Transcriptional activity of positive transcription elongation factor $\mathrm{b}$ kinase in vivo requires the C-terminal domain of RNA polymerase II. Gene 254: 139-145. CrossRef Medline

Narita M, Suzuki M, Narita M, Niikura K, Nakamura A, Miyatake M, Aoki T, Yajima Y, Suzuki T (2005) Involvement of spinal metabotropic glutamate receptor 5 in the development of tolerance to morphine-induced antinociception. J Neurochem 94:1297-1305. CrossRef Medline

Ouyang S, Song Y, Tian Y, Chen Y, Yu X, Wang D (2015) RNF8 deficiency results in neurodegeneration in mice. Neurobiol Aging 36:2850-2860. CrossRef Medline

Patel DJ, Wang Z (2013) Readout of epigenetic modifications. Annu Rev Biochem 82:81-118. CrossRef Medline

Pavri R, Zhu B, Li G, Trojer P, Mandal S, Shilatifard A, Reinberg D (2006) Histone H2B monoubiquitination functions cooperatively with FACT to regulate elongation by RNA polymerase II. Cell 125:703-717. CrossRef Medline

Phatnani HP, Greenleaf AL (2006) Phosphorylation and functions of the RNA polymerase II CTD. Genes Dev 20:2922-2936. CrossRef Medline

Shema E, Kim J, Roeder RG, Oren M (2011) RNF20 inhibits TFIISfacilitated transcriptional elongation to suppress pro-oncogenic gene expression. Mol Cell 42:477-488. CrossRef Medline

Shiloh Y, Shema E, Moyal L, Oren M (2011) RNF20-RNF40: a ubiquitin- 
driven link between gene expression and the DNA damage response. FEBS Lett 585:2795-2802. CrossRef Medline

Sorkin LS, Doom CM (2000) Epineurial application of TNF elicits an acute mechanical hyperalgesia in the awake rat. J Peripher Nerv Syst 5:96-100. CrossRef Medline

Tarcic O, Pateras IS, Cooks T, Shema E, Kanterman J, Ashkenazi H, Boocholez H, Hubert A, Rotkopf R, Baniyash M, Pikarsky E, Gorgoulis VG, Oren M (2016) RNF20 links histone H2B ubiquitylation with inflammation and inflammation-associated cancer. Cell Rep 14:1462-1476. CrossRef Medline

Wu L, Zee BM, Wang Y, Garcia BA, Dou Y (2011) The RING finger protein MSL2 in the MOF complex is an E3 ubiquitin ligase for H2B K34 and is involved in crosstalk with H3 K4 and K79 methylation. Mol Cell 43:132_144. CrossRef Medline

Wu L, Li L, Zhou B, Qin Z, Dou Y (2014) H2B ubiquitylation promotes RNA pol II processivity via PAF1 and pTEFb. Mol Cell 54:920-931. CrossRef Medline

Xiao T, Kao CF, Krogan NJ, Sun ZW, Greenblatt JF, Osley MA, Strahl BD (2005) Histone H2B ubiquitylation is associated with elongating RNA polymerase II. Mol Cell Biol 25:637-651. CrossRef Medline

Yun HJ, Yoon JH, Lee JK, Noh KT, Yoon KW, Oh SP, Oh HJ, Chae JS, Hwang SG, Kim EH, Maul GG, Lim DS, Choi EJ (2011) Daxx mediates activation-induced cell death in microglia by triggering MST1 signalling. EMBO J 30:2465-2476. CrossRef Medline
Zhang L, Berta T, Xu ZZ, Liu T, Park JY, Ji RR (2011) TNF-alpha contributes to spinal cord synaptic plasticity and inflammatory pain: distinct role of TNF receptor subtypes 1 and 2. Pain 152:419-427. CrossRef Medline

Zhang XY, Pfeiffer HK, Thorne AW, McMahon SB (2008) USP22, an hSAGA subunit and potential cancer stem cell marker, reverses the polycomb-catalyzed ubiquitylation of histone H2A. Cell Cycle 7:15221524. CrossRef Medline

Zhang Y, Wang J, Ji LJ, Li L, Wei M, Zhen S, Wen CC (2017) Identification of key gene modules of neuropathic pain by co-expression analysis. J Cell Biochem 118:4436-4443. CrossRef Medline

Zhou CH, Zhang MX, Zhou SS, Li H, Gao J, Du L, Yin XX (2017) SIRT1 attenuates neuropathic pain by epigenetic regulation of mGluR1/5 expressions in type 2 diabetic rats. Pain 158:130-139. CrossRef Medline

Zhu B, Zheng Y, Pham AD, Mandal SS, Erdjument-Bromage H, Tempst P, Reinberg D (2005) Monoubiquitination of human histone H2B: the factors involved and their roles in HOX gene regulation. Mol Cell 20:601611. CrossRef Medline

Zimmermann M (1983) Ethical guidelines for investigations of experimental pain in conscious animals. Pain 16:109-110. CrossRef Medline

Zimmermann M (2001) Pathobiology of neuropathic pain. Eur J Pharmacol 429:23-37. CrossRef Medline 